\title{
TGF $\beta 1$-Induced Differentiation of Human Bone Marrow-Derived MSCs Is Mediated by Changes to the Actin Cytoskeleton
}

\author{
Mona Elsafadi, ${ }^{1,2,3}$ Muthurangan Manikandan, ${ }^{1}$ Sami Almalki, ${ }^{4}$ Mohammad Mobarak, \\ Muhammad Atteya, ${ }^{1,6}$ Zafar Iqbal, ${ }^{7}$ Jamil Amjad Hashmi, ${ }^{8}$ Sameerah Shaheen, ${ }^{1}$ \\ Nehad Alajez $\mathbb{D},{ }^{1}$ Musaad Alfayez, ${ }^{1}$ Moustapha Kassem $\mathbb{D}^{1},{ }^{1,2,3}$ Raed Abu Dawud, \\ and Amer Mahmood ${ }^{1}{ }^{1}$ \\ ${ }^{1}$ Stem Cell Unit, Department of Anatomy, College of Medicine, King Saud University, Riyadh, Saudi Arabia \\ ${ }^{2} K M E B$, Department of Endocrinology, University Hospital of Odense, Odense, Denmark \\ ${ }^{3}$ KMEB, Department of Endocrinology, University of Southern Denmark, Odense, Denmark \\ ${ }^{4}$ College of Agriculture, King Saud University, Riyadh, Saudi Arabia \\ ${ }^{5}$ Department of Histopathology, College of Medicine, King Saud University, Riyadh, Saudi Arabia \\ ${ }^{6}$ Department of Histology, Faculty of Medicine, Cairo University, Cairo, Egypt \\ ${ }^{7}$ Department of Basic Sciences, College of Applied Medical Sciences, King Saud Bin Abdulaziz University for Health Sciences (KSAU- \\ HS), National Guard Health Affairs, Al Ahsa, Saudi Arabia \\ ${ }^{8}$ Center for Genetics and Inherited Diseases, Taibah University, Medina, Al Madinah, Saudi Arabia \\ ${ }^{9}$ Department of Comparative Medicine, King Faisal Specialist Hospital and Research Centre, Riyadh, Saudi Arabia
}

Correspondence should be addressed to Amer Mahmood; ammahmood@ksu.edu.sa

Received 26 September 2017; Accepted 23 November 2017; Published 15 February 2018

Academic Editor: Andrea Ballini

Copyright (c) 2018 Mona Elsafadi et al. This is an open access article distributed under the Creative Commons Attribution License, which permits unrestricted use, distribution, and reproduction in any medium, provided the original work is properly cited.

TGF $\beta$ is a potent regulator of several biological functions in many cell types, but its role in the differentiation of human bone marrow-derived skeletal stem cells (hMSCs) is currently poorly understood. In the present study, we demonstrate that a single dose of TGF $\beta 1$ prior to induction of osteogenic or adipogenic differentiation results in increased mineralized matrix or increased numbers of lipid-filled mature adipocytes, respectively. To identify the mechanisms underlying this TGF $\beta$ mediated enhancement of lineage commitment, we compared the gene expression profiles of TGF $\beta 1$-treated hMSC cultures using DNA microarrays. In total, 1932 genes were upregulated, and 1298 genes were downregulated. Bioinformatics analysis revealed that TGF $\beta 1$ treatment was associated with an enrichment of genes in the skeletal and extracellular matrix categories and the regulation of the actin cytoskeleton. To investigate further, we examined the actin cytoskeleton following treatment with TGF $\beta 1$ and/or cytochalasin D. Interestingly, cytochalasin D treatment of hMSCs enhanced adipogenic differentiation but inhibited osteogenic differentiation. Global gene expression profiling revealed a significant enrichment of pathways related to osteogenesis and adipogenesis and of genes regulated by both TGF $\beta 1$ and cytochalasin D. Our study demonstrates that TGF $\beta 1$ enhances hMSC commitment to either the osteogenic or adipogenic lineages by reorganizing the actin cytoskeleton.

\section{Introduction}

Fat and bone tissues both originate from bone marrow progenitor cells called skeletal stem cells, also known as bone marrow-derived multipotent stromal cells or mesenchymal stem cells (MSCs). The formation of these tissues is regulated throughout an organism's lifetime by homeostatic mechanisms within the marrow cavity. It has been suggested that an imbalance between osteogenic and adipogenic lineage commitment and differentiation is 
responsible for age-related impairment of bone formation, and number of therapeutic interventions targeting and activating MSCs, thus enhancing bone mass, have been proposed. Indeed, the identification of novel strategies to steer human skeletal (mesenchymal) stem cell differentiation towards the production of osteoblastic cells, thus increasing bone formation, is very topical in the bone biology field.

The transforming growth factor (TGF) superfamily consists of over 40 members, including activins, inhibins, bone morphogenetic proteins (BMPs), growth and differentiation factors (GDFs), and TGF $\beta$ s [1]. TGF family members are multifunctional regulators of cell growth and differentiation, playing pivotal roles during embryonic development, organogenesis, and tissue homeostasis [2]. The cytokine TGF $\beta 1$ is among the most abundant in bone matrix [3] and is secreted by endothelial cells, epithelial cells, fibroblasts, smooth muscle cells, and most immune cells [4]. TGF $\beta 1$ is deposited in bone matrix as an inactive, latent complex with latencyassociated protein (LAP), the binding of which masks the receptor domains of active TGF $\beta 1$. During bone formation, osteoclast-mediated bone resorption activates TGF $\beta 1$ by cleaving LAP and releasing it from bone matrix, thus creating a transient gradient of active TGF $\beta 1$ that attracts MSCs to bone remodeling sites, where they undergo osteoblastic differentiation [5]. Furthermore, TGF $\beta 1$ is known to regulate the proliferation and differentiation of osteoprogenitor cells [6].

Actin microfilaments are composed of polymers of actin, the most abundant cellular protein which also forms the thinnest part of the cytoskeleton, and are primarily responsible for skeletal structure [7]. Cellular actin exists in two forms, filamentous polymerized actin (F-actin) and globular/monomer depolymerized actin (G-actin), and transitions between these forms during highly dynamic intracellular polymerization and depolymerization processes [8]. In mammals, actin polymerization factors regulate actin polymerization and depolymerization [9]. While the stiffness of actin is lower than that of microtubules, actin molecules form a highly organized structural network, supported by a large number of interacting cross-linking proteins, which together confer a substantial amount of mechanical strength [10]. The cytoskeleton is known to be important for determining cell morphology and for mediating changes in adhesion and differentiation [11]. Indeed, during human MSC (hMSC) lineage commitment, cells undergo significant morphological changes and actin cytoskeletal reorganization which contribute to the determination of cellular fate $[7,12]$.

In this study, we investigated the effect of TGF $\beta$-induced actin cytoskeleton modifications on the potential of hMSCs to differentiate into osteogenic and adipogenic lineages, as well as the effect of the actin polymerization inhibitor cytochalasin D (CYD). Our data suggest that TGF $\beta$-induced actin cytoskeleton reorganization is a prerequisite for hMSC differentiation into osteocytic or adipocytic lineages.

\section{Results}

2.1. TGF $\beta 1$ Treatment Enhanced the Osteogenic Differentiation of hMSCs. A single treatment with TGF $\beta 1(10 \mathrm{ng} / \mathrm{ml}$, for 2 days) enhanced hMSC osteogenic differentiation, as shown by the increased mineralized matrix formation made evident by alizarin red S staining (Figures $1(\mathrm{a})$ and $1(\mathrm{~b})$ ). Conversely, when TGF $\beta 1$ signaling was blocked with the inhibitor SB$431542(10 \mu \mathrm{M})$, significantly lower mineralized matrix formation was observed (Figures 1(a) and 1(b)). Consistent with this, higher expression of the osteoblastic genes alkaline phosphatase $(A L P)$, runt-related transcription factor 2 (RUNX2), and osteocalcin $(O C N)$ was observed in hMSCs undergoing osteogenic differentiation in the presence of TGF $\beta 1$, while treatment with the TGF $\beta 1$ inhibitor SB-431542 severely inhibited this expression (Figure 1(c)).

2.2. TGF $\beta 1$ Treatment Enhanced the Adipogenic Differentiation of hMSCs. Next, we examined the effect of treating hMSCs with a single dose of TGF $\beta 1(10 \mathrm{ng} / \mathrm{ml}$, for 2 days $)$ on adipogenic differentiation. We found that adipogenic differentiation was enhanced following TGF $\beta 1$ treatment, as shown by an increase in the number of lipid-filled adipocytes (Figures 1(d) and 1(e)). Similarly, the expression of several adipogenic gene markers, including lipoprotein lipase $(L P L)$, peroxisome proliferator-activated receptor gamma 2 (PPARG-2), adipocyte protein $2(a P 2)$, and ADIPOQ, was upregulated following TGF $\beta 1$ treatment, while treatment with SB-431542 reversed these effects (Figure 1(f)).

2.3. TGF $\beta 1$ Stimulation Has No Effect on hMSC Viability or Proliferation. The effect of TGF $\beta 1$ on hMSC cell viability was assessed using alamarBlue assay reagent. No significant effect on viability was observed after 4 days of treatment (Figure 2(a)). To investigate the effect of TGF $\beta 1$ on cellular proliferation, we used the xCELLigence RTCA DP ${ }^{\circledR}$ cell proliferation assay system, which allows the continuous monitoring of cell numbers over time. As shown in Figure 2(b), there was no measurable difference in hMSC proliferation in the presence or absence of TGF $\beta 1$.

2.4. Molecular Phenotype of TGF $\beta 1$-Treated hMSCs. To understand the molecular mechanisms underlying the TGF $\beta 1$-mediated regulation of hMSC differentiation, we compared global gene expression in TGF $\beta$ l-treated hMSCs and vehicle-treated control cells using microarray analysis. In total, 1932 gene transcripts were significantly upregulated, and 1298 were significantly downregulated following TGF $\beta 1$ treatment. Significant changes were defined as a fold change $\geq 2, p<0.05$ and are listed in Supplementary Tables S1 and S2. Hierarchical clustering of differentially expressed genes revealed a clear distinction between TGF $\beta 1$-treated and control samples (Figure 3(a)). Next, we used performed gene ontology analysis to identify the biological processes that were favored following TGF $\beta$ l treatment. We found that the genes that were significantly altered in TGF $\beta 1$-treated MSCs were enriched within several skeletal and extracellular matrix categories, including extracellular matrix (53 genes), extracellular matrix organization (51 genes), and proteinaceous extracellular matrix (Supplementary Table S3). Furthermore, pathway analysis of significantly changed genes revealed the significant enrichment of several signaling pathways in TGF $\beta$ l-treated hMSCs. Among these, the most 

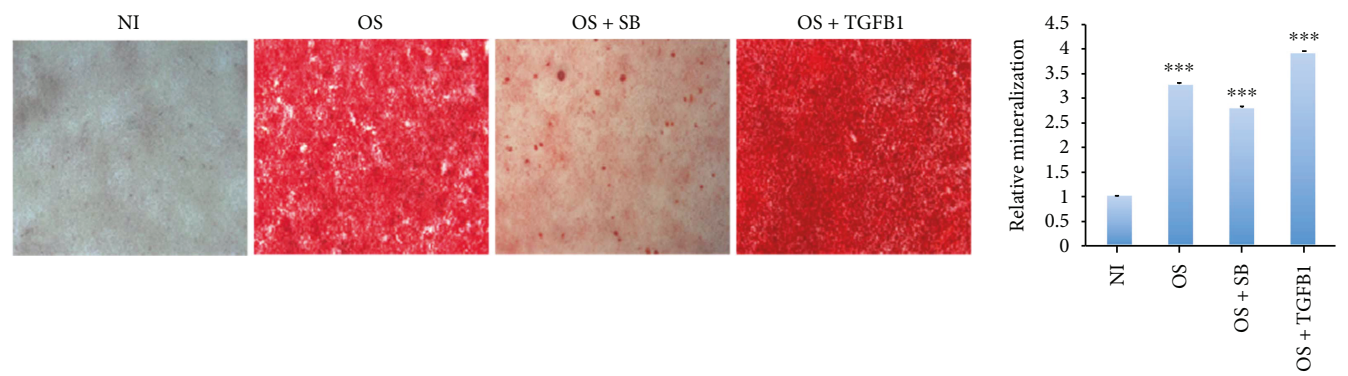

(a)

(b)
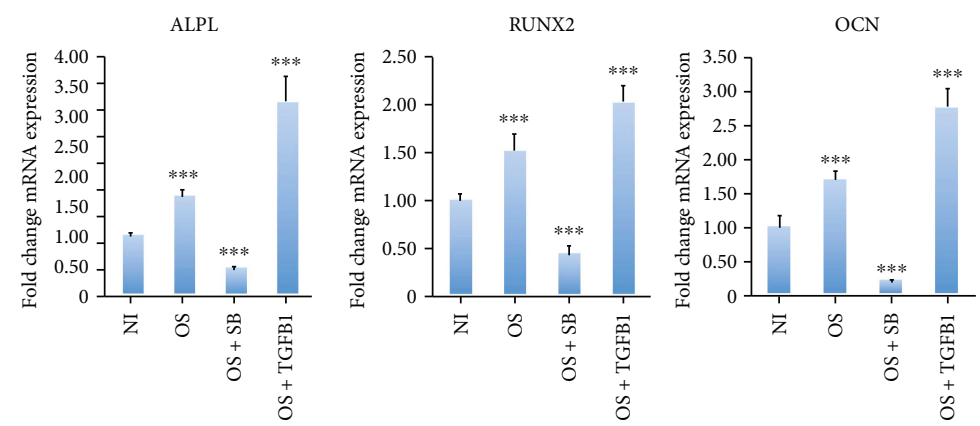

(c)

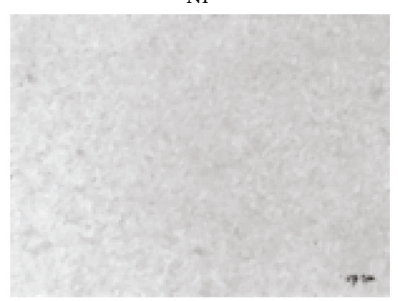

$\mathrm{AD}$

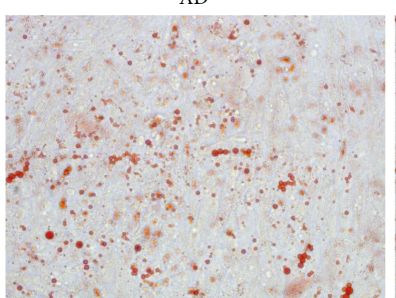

$\mathrm{AD}+\mathrm{SB}$
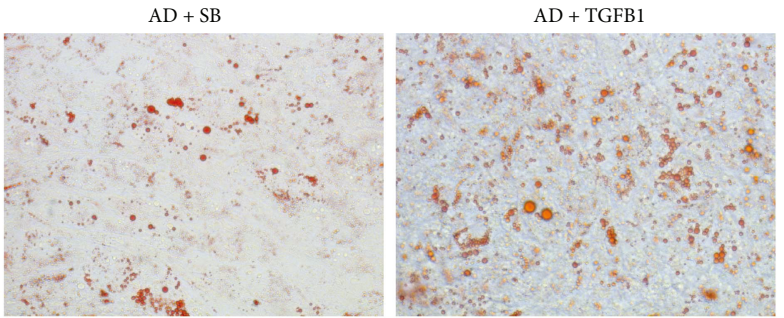

(d)

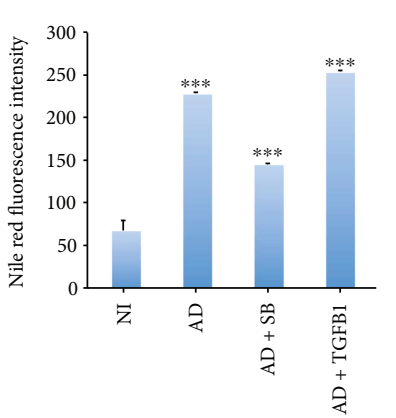

(e)

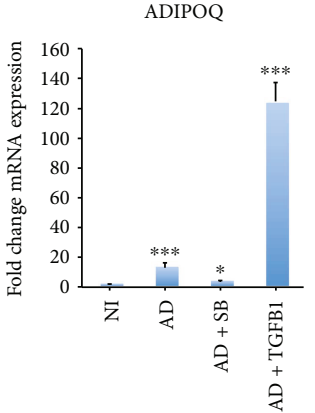

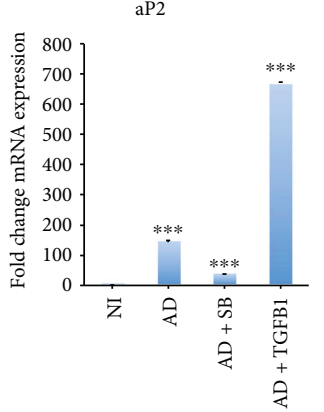

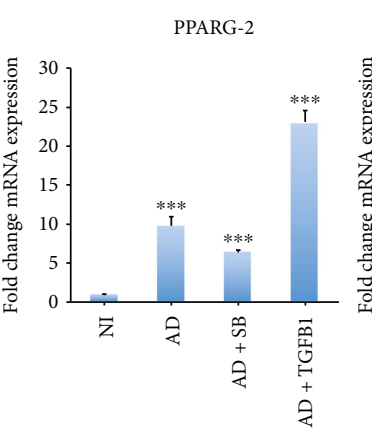

(f)

FIGURE 1: TGF $\beta 1$ induces osteogenic and adipogenic differentiation. MSCs underwent osteogenic or adipogenic differentiation by culturing cells in the appropriate medium for 7 days. (a) Micrographs showing the degree of mineralized calcium deposition in noninduced cells (NI), osteoinduced cells (OS), osteoinduced cells + SB-431542 (OS + SB), and osteoinduced cells + TGF $\beta 1$ (OS + TGFB), as assessed by alizarin red S staining (20x magnification). (b) Quantification of mineralization in the alizarin red S stained groups shown in (a). Data are shown as the mean $\pm \mathrm{SD}$ of three independent experiments $\left({ }^{* * *} p<0.005\right)$. (c) mRNA expression of the osteogenic markers $A L P L$, RUNX2, and OCN, normalized to GAPDH, as determined by RT-PCR. Data are shown as the mean $\pm \mathrm{SD}$ of three independent experiments $\left({ }^{*} p<0.05 ;{ }^{* * *} p<0.0005\right)$. (d) Micrographs showing the accumulation of lipid droplets in noninduced cells (NI), adipoinduced cells (AD), adipoinduced cells + SB-431542 (AD + SB), and adipoinduced cells + TGF $\beta 1(A D+T G F B)$, as determined by Oil red $\mathrm{O}$ staining (20x magnification). (e) Quantification of mature adipocytes in the $\mathrm{NI}, \mathrm{AD}, \mathrm{AD}+\mathrm{SB}$, and $\mathrm{AD}+\mathrm{TGFB}$ groups, as determined by Nile red fluorescence intensity. Data are shown as the mean $\pm \mathrm{SD}$ of three independent experiments $\left({ }^{* * *} p<0.005\right)$. (f) mRNA expression of the adipogenic markers $L P L, a P 2, P P A R G-2$, and $A D I P O Q$, normalized to GAPDH, as determined by RT-PCR. Data are shown as the mean $\pm \mathrm{SD}$ of three independent experiments $\left({ }^{*} p<0.05 ;{ }^{* * *} p<0.0005\right)$. 


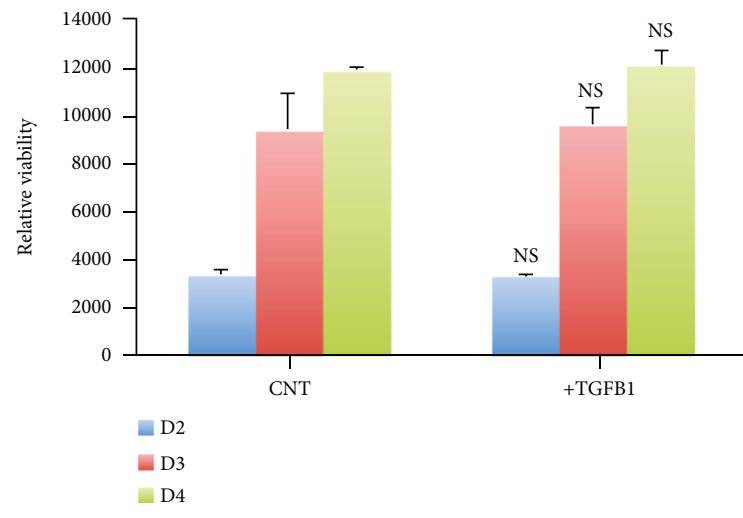

(a)
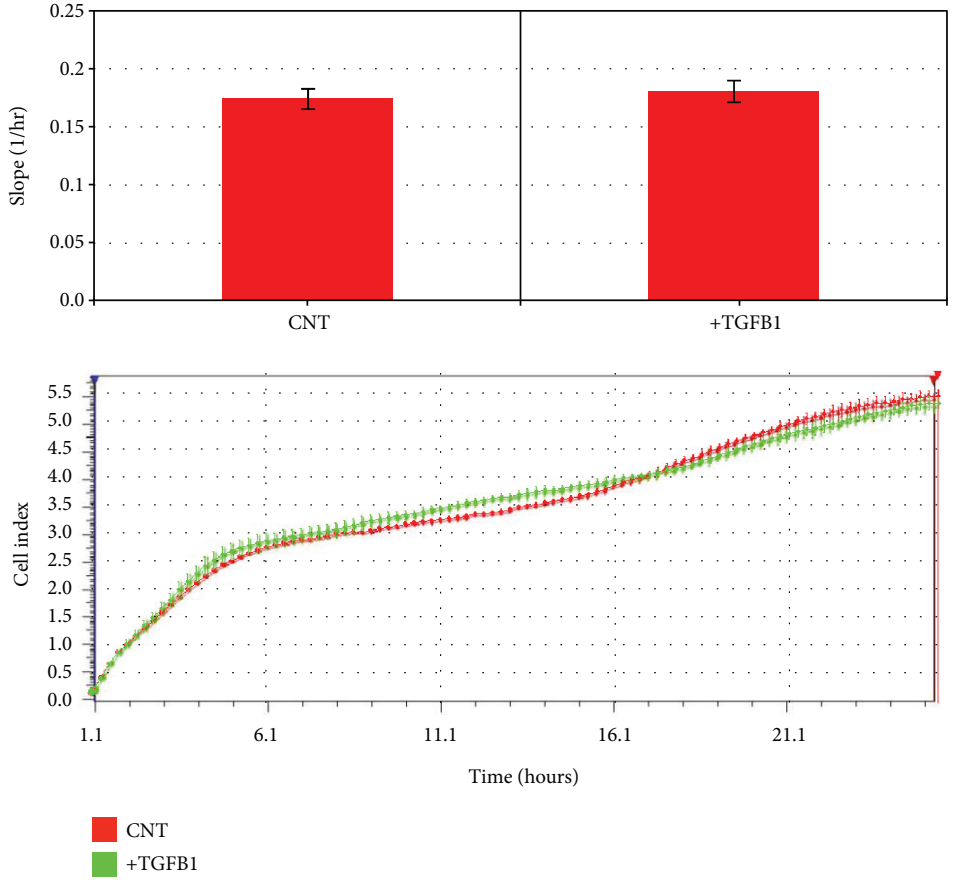

(b)

FIgURE 2: TGF $\beta 1$ does not affect hMSC proliferation or viability. (a) Chart showing the relative hMSC viability in the absence (CNT) or presence (TGFB1) of TGF $\beta 1$, as determined by alamarBlue assay reagent. Shown are cell viabilities on days 2 (D2), 3 (D3), and 4 (D4) of culture. (b) Real-time proliferation assay data using the xCELLigence RTCA DP system for hMSC cells with and without TGF $\beta 1$ treatment. Lower panel: cell proliferation was measured at 15-minute intervals for a total duration of 24 hours. Upper panel: summary data showing cellular proliferation after 24 hours. Data are shown as the mean \pm SD of two independent experiments ( $n=6)$. NS: not significant.

enriched pathways were "regulation of actin cytoskeleton," "MAPK signaling," "focal adhesion," "TGF $\beta 1$ signaling," "adipogenesis," "endochondral ossification," and "osteoblast signaling" (Figure 3(b)). Table 1 lists the genes within osteogenesis- and adipogenesis-related signaling pathways that were upregulated in TGF $\beta 1$-treated cells. A selected panel of genes known to be involved in cell differentiation and TGF $\beta$ signaling that were significantly changed in the microarray data were examined by qRT-PCR. In general, a good degree of concordance was observed between the microarray and qRT-PCR data (Figure 3(c)).

2.5. Actin Microfilaments in MSCs Are Altered following Treatment with TGF $\beta 1$ or the Actin Polymerization Inhibitor $C Y D$. Our molecular phenotyping analysis of TGF $\beta 1-$ treated hMSCs revealed a significant enrichment of genes associated with cytoskeletal changes. Based on this, and on our previous observations that TGF $\beta$ l treatment triggers significant morphological changes in hMSCs, we examined the effect of TGF $\beta 1$ on the cytoskeleton using transmission electron microscopy (TEM), which has the power to reveal structural changes in actin microfilaments. Actin microfilament polymerization was found to be inhibited in cells treated with either the potent actin polymerization inhibitor CYD or the TGF $\beta$ inhibitor SB-431542. In contrast, TGF $\beta 1$ treatment was associated with a prominent distribution of actin filaments, organized as bundles/aggregates, in the perinuclear area and at one cell pole (Figure 4). The ultrastructural characteristics of the cells under the various treatment conditions are summarized in Supplementary Table S4.

2.6. CYD Regulates Osteogenic and Adipogenic Differentiation in the Presence of TGF $\beta 1$. To confirm that TGF $\beta 1$ regulates actin cytoskeletal dynamics, hMSCs undergoing either osteogenic or adipogenic differentiation were treated with TGF $\beta 1$ in the absence or presence of the actin polymerization inhibitor CYD. CYD treatment significantly inhibited hMSC osteogenic differentiation in both the presence and absence of TGF $\beta 1$, as shown by reduced mineralization (Figure 5(a)). Similarly, expression of the osteogenic marker genes $A L P L$, RUNX2, and OCN was inhibited by CYD treatment, with and without TGF $\beta 1$ (Figure 5(b)). Conversely, CYD treatment enhanced hMSC adipogenic differentiation, as shown by a greatly increased number of lipid-filled mature adipocytes and the increased expression of the adipogenic marker genes LPL and PPARG-2. These effects were maintained when cells were treated concomitantly with TGF $\beta 1$ (Figures 5(c) and 5(d)).

2.7. Molecular Phenotype of CYD-Treated Cells. The data presented above suggest that CYD and TGF $\beta 1$ target similar molecular pathways during hMSC osteogenic and adipogenic differentiation. In order to investigate this further and to elucidate the molecular mechanisms underlying the CYD- 


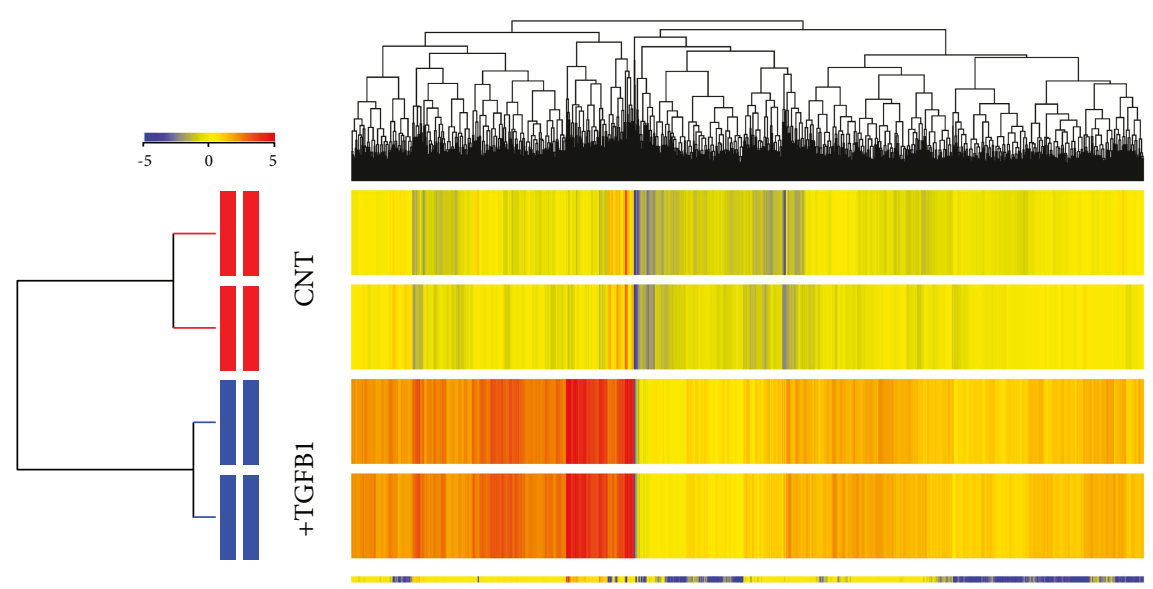

(a)

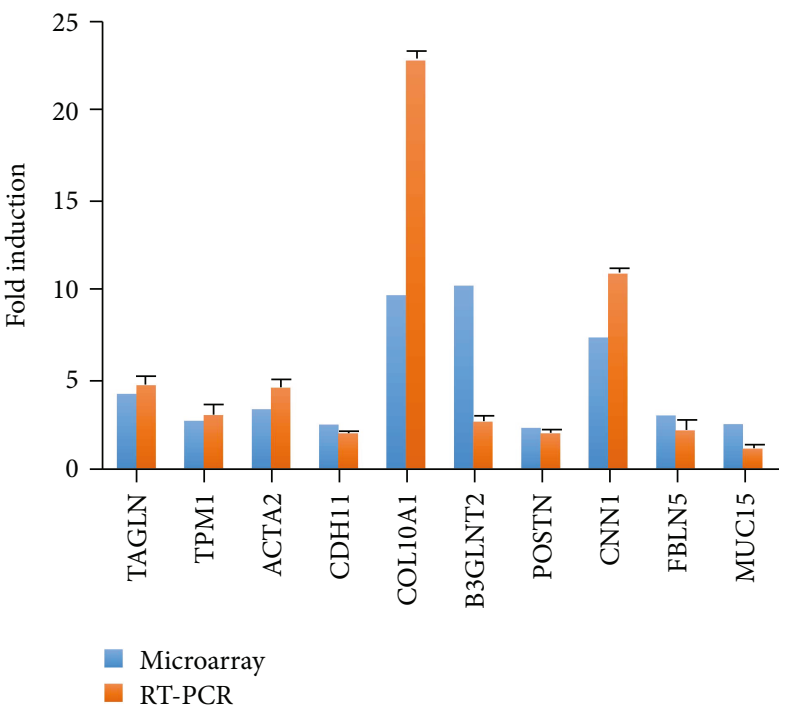

(c)

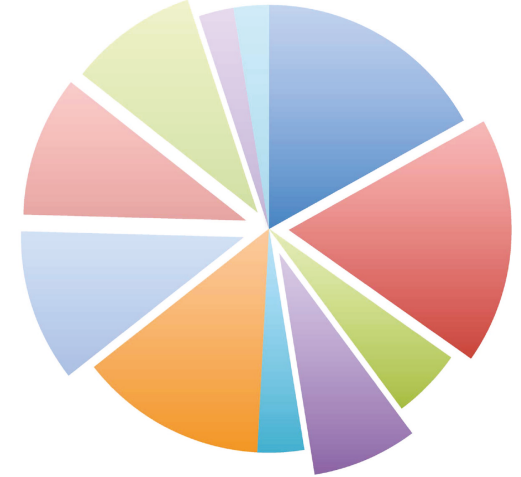

Hs MAPK signaling pathway WP382 41 048

- Hs Focal adhesion WP306 45270

Hs Cell junction organization WP1793 44989

Hs Endochondral ossification WP474 4 5000

Hs Integrin cell surface interactions W P1833 44861

Hs Insulin signaling WP481 42706

Hs Regulation of actin cytoskeleton W P51 45278

- Hs Adipogenesis WP236 41040

Hs TGF beta signaling pathway WP366 45152

1- Hs Osteoblast signaling WP322 45323

Figure 3: Molecular phenotype of TGF $\beta 1$-treated hMSCs. (a) Hierarchical clustering of genes that were differentially expressed in TGF $\beta 1$ treated and untreated control (CNT) hMSCs. Rows represent individual gene expression for duplicate treated and untreated samples, as indicated. Columns represent individual transcripts. Relative expression levels are presented colorimetrically, according to the scale shown in the color bar. (b) Pie chart showing the pathways with the highest enrichment of genes significantly upregulated in TGF $\beta 1$-treated cells. (c) qRT-PCR validation of selected genes that were upregulated in the microarray data $\left(n=3,{ }^{*} p<005 ;{ }^{* * *} p<0001\right)$. Cells treated with vehicle (DMSO) were used as controls.

mediated effects on hMSC differentiation, microarray analysis was performed to establish global gene expression profiles for CYD-treated and controls cells. In total, 10,855 genes were significantly upregulated, and 2523 genes were significantly downregulated following CYD treatment. Genes were defined as significantly changed if they had a fold change $\geq 2$ and $p<0.05$ and are listed in Supplementary Tables S5 and S6. As was seen with TGF $\beta 1$ treatment, hierarchical clustering of the differentially expressed genes revealed a clear distinction between untreated and CYD-treated hMSCs (Figure 6(a)). Pathway analysis of these genes revealed several molecular pathways that were enriched upon CYD treatment (Figure 6(b)). Among the most significant were pathways involved in the regulation of the actin cytoskeleton, focal adhesion signaling, endochondral ossification, TGF $\beta 1$ signaling, regulation of the microtubule cytoskeleton, and
MAPK signaling (Figure 6(b)). The genes that are associated with these pathways that were upregulated in CYD-treated cells are listed in Table 2. Forty-two genes that are involved in adipogenesis-related pathways were significantly enriched in CYD-treated cells (Table 3). Interestingly, 218 genes were both upregulated in TGF $\beta 1$-treated hMSCs and downregulated in CYD-treated hMSCs (Figure 6(c)), showing that the molecular signature on CYD treatment is the inverse of that seen with TGF $\beta 1$ treatment and suggesting that these genes may be involved in TGF $\beta$-mediated cytoskeletal reorganization (Table 4).

\section{Discussion}

$\operatorname{TGF} \beta$ is a potent regulator of various biological functions in many cell types, but its effects on hMSC differentiation are, to 
TABLE 1: Osteogenesis- and adipogenesis-related genes, from the most enriched pathways, that are upregulated in TGF $\beta 1$-treated cells.

\begin{tabular}{|c|c|c|c|c|c|}
\hline Endochondral ossification & Actin cytoskeleton & Focal adhesion & TGF $\beta$ signaling & MAPK signaling & Adipogenesis \\
\hline VEGFA & FGF2 & COL11A1 & SMURF1 & MAPK8 & FOXO1A \\
\hline ADAMTS4 & FGFR1 & COL3A1 & MAPK8 & NGFB & TRIB3 \\
\hline PLAT4 & TMSB4X & COL4A1 & SKP1 & PDGFRB & PCK2 \\
\hline COL10A1 & GNA13 & COL4A2 & NEDD9 & RASA2 & EGR2 \\
\hline TGFB2 & PDGFA & COL4A4 & ETS1 & SOS2 & DDIT3 \\
\hline PTHrP & FGF1 & COL5A1 & KLF11 & KRAS & GADD45A \\
\hline FGF2 & ENAH & COL5A2 & ATF3 & MRAS & GADD45B \\
\hline C4ST1 & MSN & COL1A1 & FOSB & NF1 & HIF1A \\
\hline FGFR1 & GSN & LAMC2 & SKIL & RAP1B & IRS1 \\
\hline PDGFRB & PDGFRB & THBS2 & SMURF1 & DUSP1 & MEF2D \\
\hline \multirow[t]{11}{*}{ COL1 } & KRAS & CAV2 & ZFYVE16 & DDIT3 & FAS \\
\hline & MRAS & ARHGAP5 & & HSPB1 & SPOCK \\
\hline & SOS2 & PTEN & & IL1A & \\
\hline & & AKT3 & & FAS & \\
\hline & & PDGFA & & TGFB2 & \\
\hline & & PDGFC & & MAP313 & \\
\hline & & PGF & & ZAK & \\
\hline & & ITGA2 & & AKT3 & \\
\hline & & PDGFRB & & MAР3К8 & \\
\hline & & RAP1B & & GADD45A & \\
\hline & & MAPK8 & & & \\
\hline
\end{tabular}

date, poorly understood. In the present study, we contribute to this understanding and demonstrate that TGF $\beta$ can enhance both osteoblastic and adipocytic lineage commitment by modulating changes to the actin cytoskeleton.

TGF $\beta 1$ is known to regulate the proliferation and differentiation of osteoprogenitor cells $[6,13-15]$, and it reportedly stimulates bone matrix apposition and bone cell replication [16]. Several studies have demonstrated that TGF $\beta 1$ promotes bone formation in vitro by recruiting osteoblast progenitors and inducing bone matrix formation at early stages of differentiation. In addition to this direct regulation of bone formation, TGF $\beta 1$, along with BMPs, enhances RUNX2 expression at early differentiation stages [17]. This is consistent with our finding that TGF $\beta 1$ promoted osteogenesis and was associated with the upregulation of the osteogenic genes $A L P L, R U N X 2$, and $O C N$.

Furthermore, we showed that TGF- $\beta 1$ treatment enhanced the in vitro adipocytic differentiation of hMSCs. This is consistent with several previously reported studies which demonstrate that TGF $\beta 1$ has a positive effect on adipogenic differentiation under specific culture conditions $[18,19]$; an early study considering rat brown adipocytes showed an upregulation of lipogenic enzymes following TGF $\beta 1$ treatment [19].

Our results showed that TGF $\beta 1$ treatment did not affect MSC cell growth in vitro. Previously, conflicting results have been published; some studies reported that TGF $\beta 1$ regulated osteoprogenitor proliferation in vitro $[13,20]$, whereas Yu et al. reported that TGF $\beta 1$ treatment strongly inhibited the proliferation of human lung epithelial cells [21]. The mitogenic effects of TGF $\beta$ on cells are reportedly variable; while progressive mitogenesis was stimulated in confluent cells following treatment with $0.15-15 \mathrm{ng} / \mathrm{ml} \mathrm{TGF} \beta$, in sparse cultures $0.15 \mathrm{ng} / \mathrm{ml}$ TGF $\beta$ exhibited inhibitory effects. However, at all cell densities, $15 \mathrm{ng} / \mathrm{ml}$ TGF $\beta$ stimulated collagen synthesis, with this effect being most pronounced when DNA synthesis was declining [22]. Most of the published data on TGF $\beta$ has shown a mitogenic effect on osteoprogenitors $[16,23-26]$, but relatively few studies have examined the growth inhibitory effect of this cytokine on osteoblast-like cells $[27,28]$. It is likely that these contradictory observations reflect the fact that the effect TGF $\beta$ has on cellular proliferation is dependent upon TGF $\beta$ concentration, culture conditions including cell density, the cell model system (tumorigenic versus nontumorigenic), the differentiation stage of the target cell population, and/or the presence of other growth factors.

The cytoskeleton is known to be important for cell morphology and for mediating changes in adhesion and differentiation [11]. Furthermore, significant changes in cytoskeletal components reportedly occur during hMSC lineage commitment and differentiation [7, 11]. While changes in cell shape can be influenced by differentiation, several studies have shown that the differentiation of precommitted mesenchymal stem cells is itself influenced by changes in cellular morphology resulting from the altered expression of cadherins, integrins, and cytoskeletal proteins [29]. Recently, the inhibition of actin depolymerization was shown to enhance both hMSC differentiation into osteoblasts and in vivo bone formation, with these effects being mediated by several 
CNT
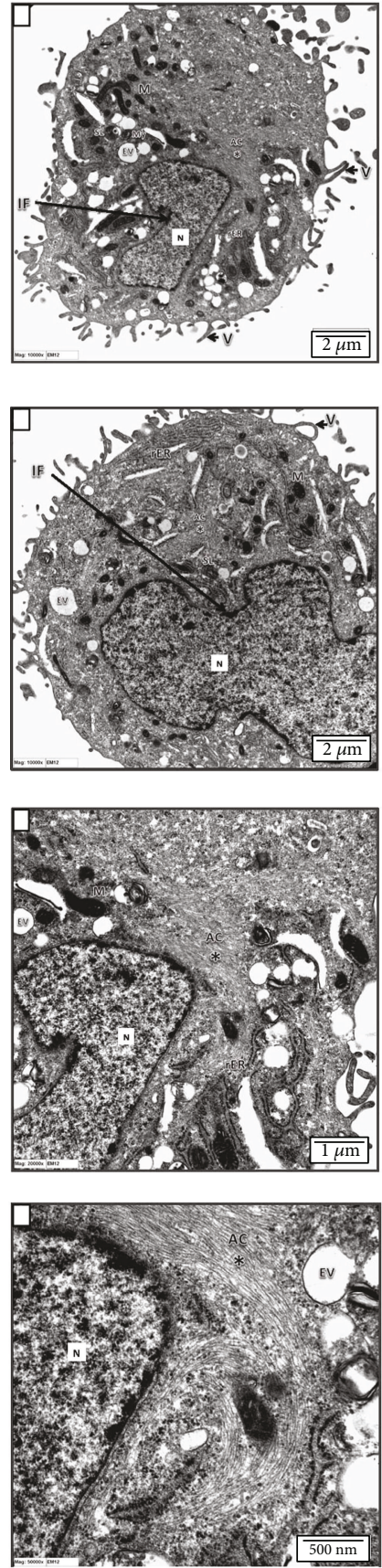

$+\mathrm{SB}$
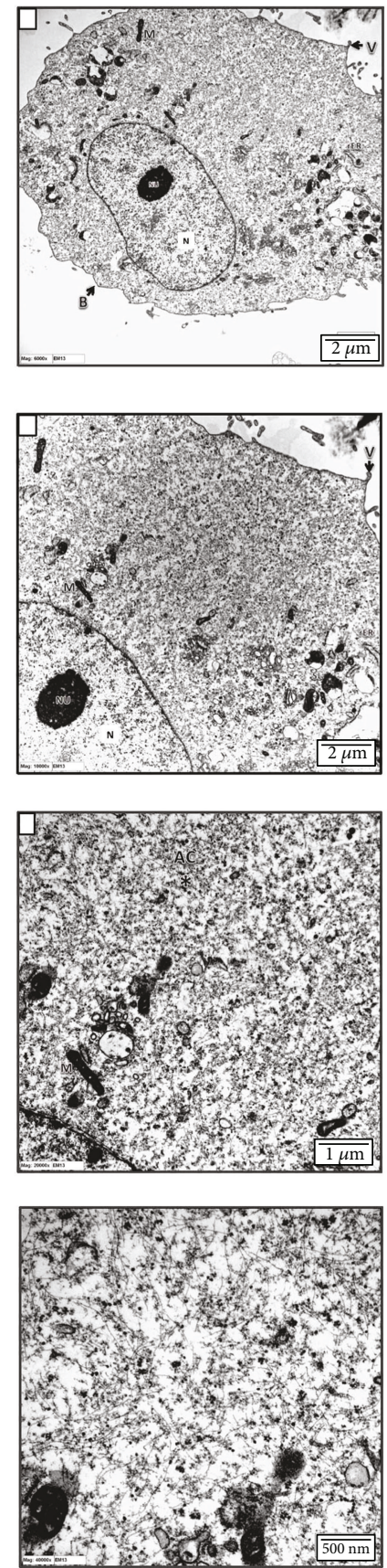

+ TGFB1
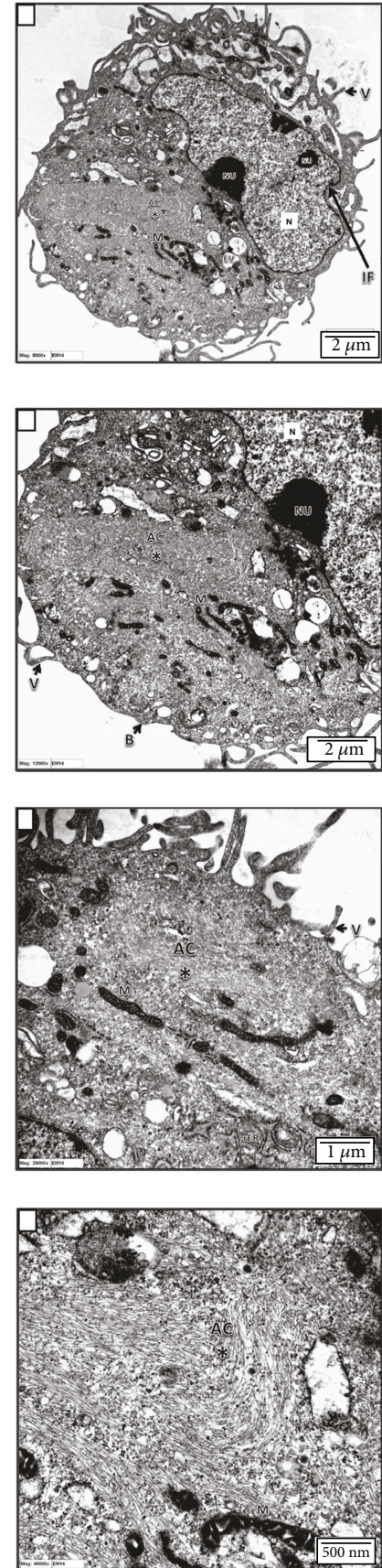

$+\mathrm{CYD}$
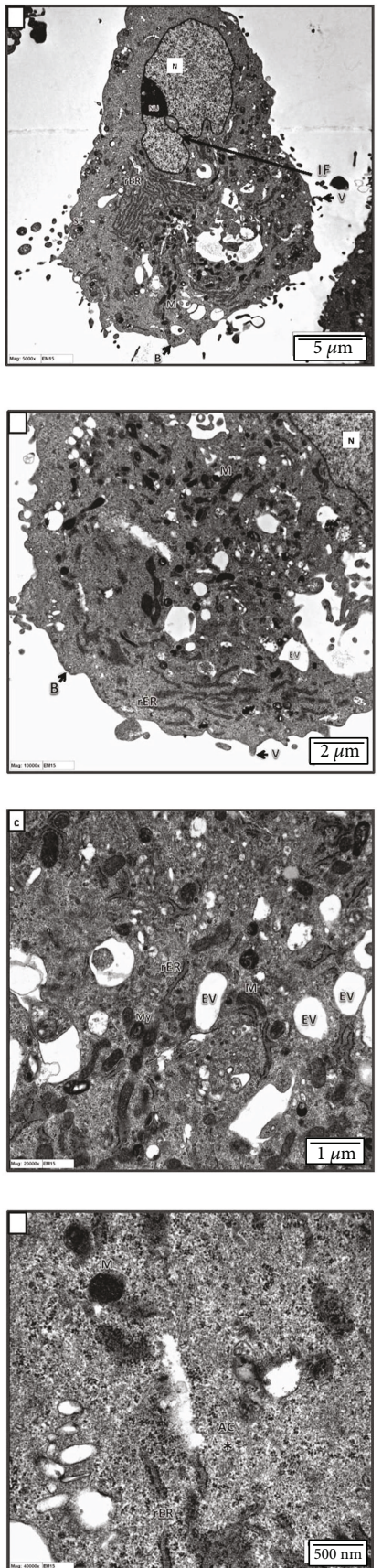

FIGURE 4: Transmission electron microscopy of MSCs with and without treatment with SB-431542, TGF $\beta 1$, or CYD. TEM ultrastructural analysis of MSCs following no treatment (CNT) or treatment with SB-431542 (SB), TGF $\beta 1$, or CYD. Increasing levels of magnification are indicated by scale bars. N: nucleus; Nu: nucleolus; AC: actin filaments; V: microvilli; M: mitochondria; PL: primary lysosome; SL: secondary lysosome; rER: rough endoplasmic reticulum; G: Golgi bodies; B: cell blebs; P: cell processes; IF: nuclear membrane infolding; EV: endocytotic vacuole.

signaling pathways and involving focal adhesion kinase (FAK), p38, and JNK activation [7]. Furthermore, a separate study reported that the suppression of actin polymerization, a very early event in hMSC differentiation, following the downregulation of p38 MAPK activity, inhibited osteogenesis [30]. Additionally, $\alpha$-smooth muscle actin is important for both the identification of osteoprogenitors in hMSCs and their differentiation fate [31], and Rho GTPase-mediated cytoskeletal modification is essential for controlling hMSC differentiation and migration [32].

On the other hand, adipocytic differentiation is associated with the morphological change from fibroblast-like cells to spherical cells filled with fat droplets [33]. These morphological alterations are also associated with cytoskeletal changes and 


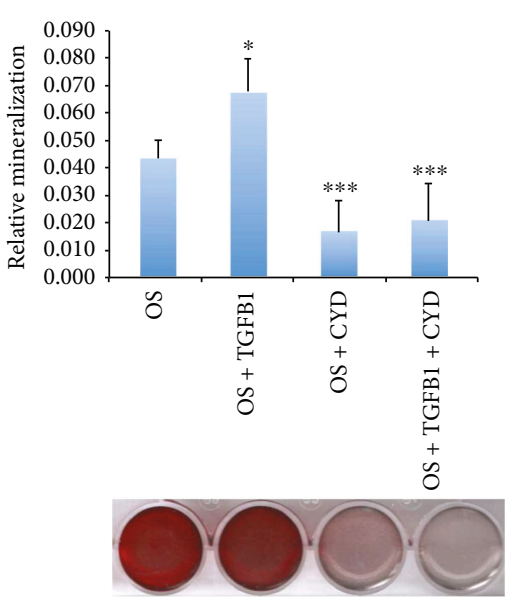

(a)

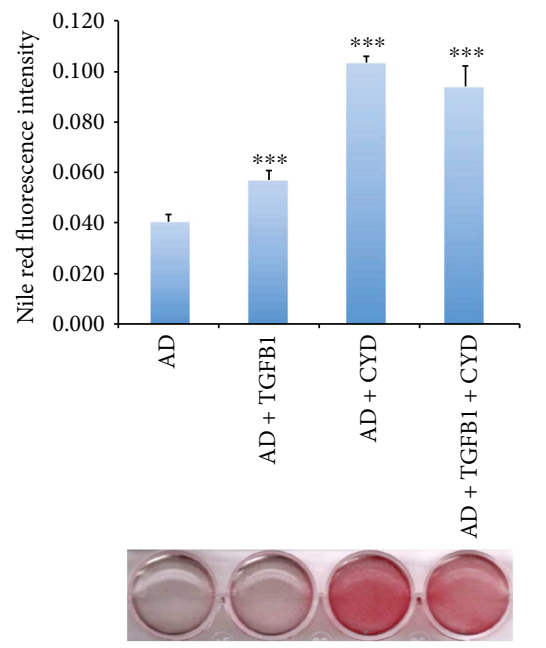

(c)
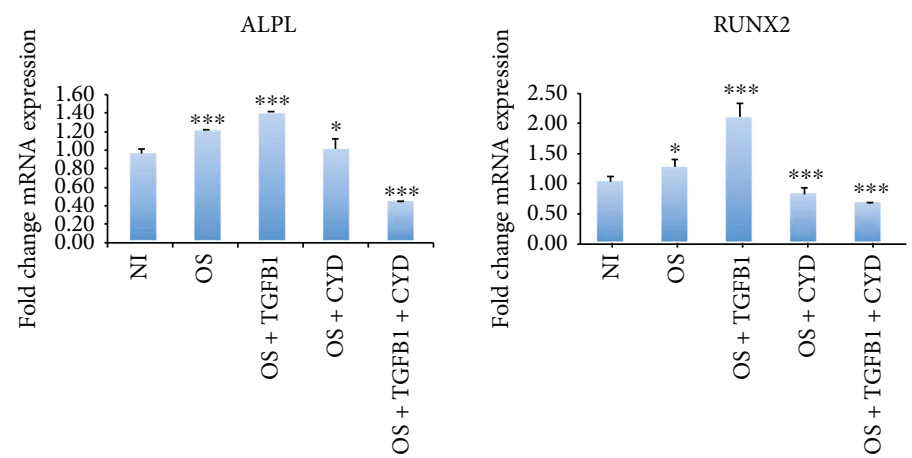

(b)
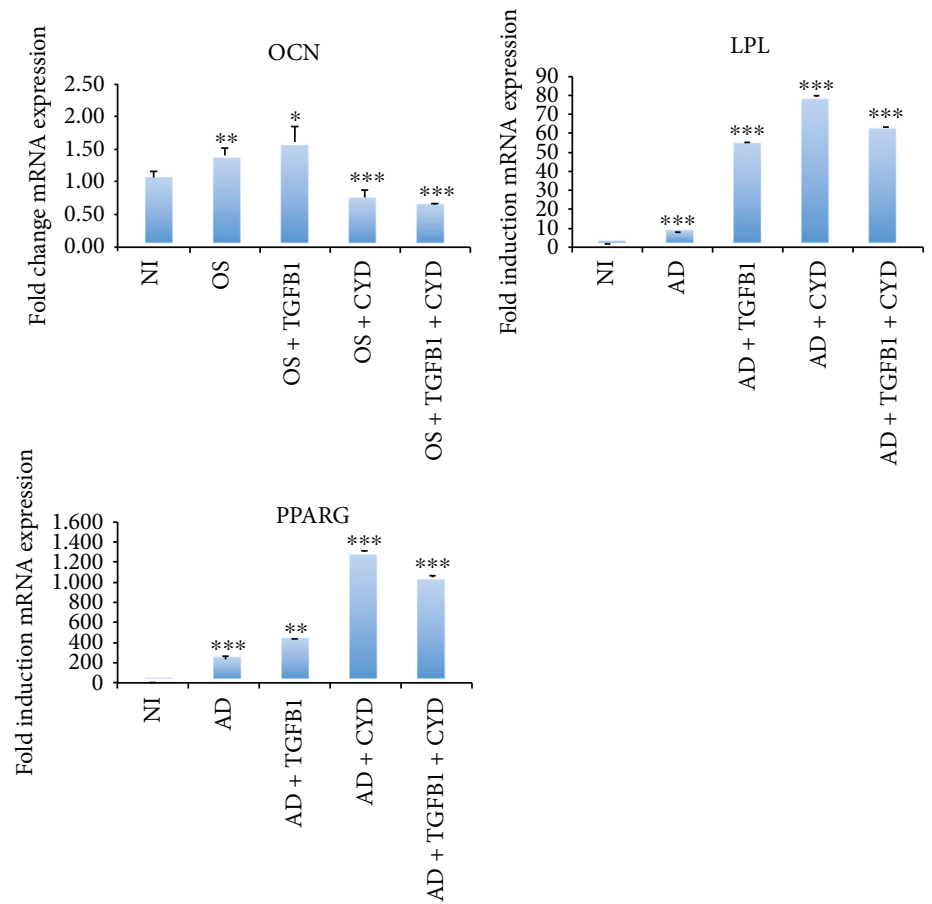

(d)

FIGURE 5: Inhibition of actin polymerization promotes adipogenic differentiation but inhibits osteogenic differentiation in MSCs. MSCs underwent osteogenic or adipogenic differentiation by culturing cells in the appropriate medium for 7 days. Cells also underwent the indicated treatments. (a) Mineralized calcium deposition, as determined by alizarin red S staining in MSCs that were osteoinduced (OS), osteoinduced with TGF $\beta 1$ treatment two days prior to induction (OS + TGF $\beta 1$ ), osteoinduced with CYD treatment at the onset of induction $(\mathrm{OS}+\mathrm{CYD})$, or osteoinduced with both TGF $\beta 1$ and CYD treatment at the time points described above (OS + TGF $\beta 1+\mathrm{CYD})$. Lower panel: micrograph of stained wells. Upper panel: quantification of mineralized matrix formation under the indicated treatment conditions. Data are shown as the mean $\pm S D$ of three independent experiments $\left({ }^{*} p<0.05 ;{ }^{* * *} p<0.005\right)$. (b) Gene expression of the osteogenic markers ALPL, RUNX2, and OCN, normalized to GAPDH, as determined by qRT-PCR. Cells were either not induced (NI) or induced under the conditions described in (a). Data are shown as the mean \pm SD of three independent experiments $\left({ }^{*} p<0.05 ;{ }^{* *} p<0.005\right.$, $\left.{ }^{* * *} p<0.0005\right)$. (c) Adipogenic differentiation of MSCs that were adipoinduced (AD), adipoinduced with TGF $\beta 1$ treatment 2 days prior to induction $(A D+T G F \beta 1)$, adipoinduced with CYD treatment, initiated at the onset of induction (AD + CYD), or adipoinduced with both TGF $\beta 1$ and CYD treatment at the time points described above (AD + TGF $\beta 1+C Y D)$. Lower panel: Oil red $O$ staining of the indicated cells. Upper panel: Nile red quantification of oil content under the indicated conditions. (d) Gene expression of the adipogenic marker genes PPARG and LPL, determined by qRT-PCR and normalized to GAPDH, under the indicated treatment regimens. Data are shown as the mean \pm SD of three independent experiments $\left({ }^{* *} p<0.005,{ }^{* * *} p<0.0005\right)$. All controls were treated with vehicle only. 


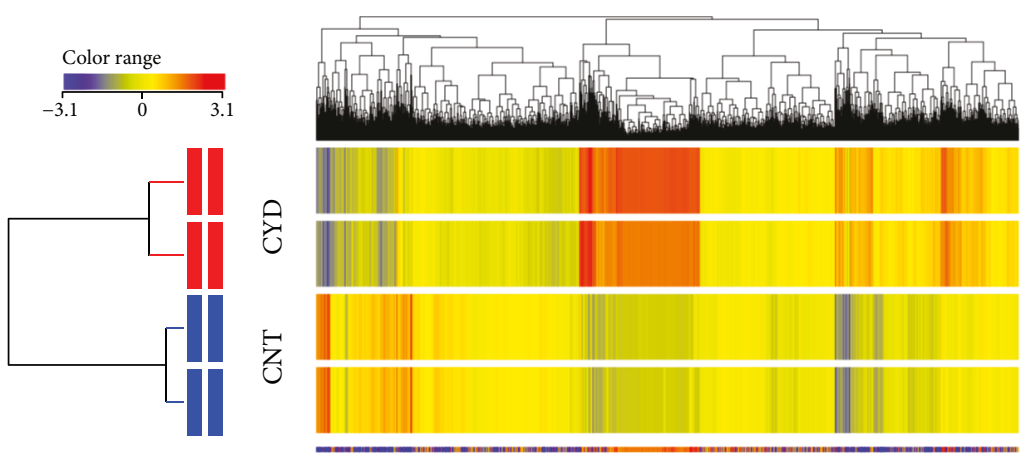

(a)

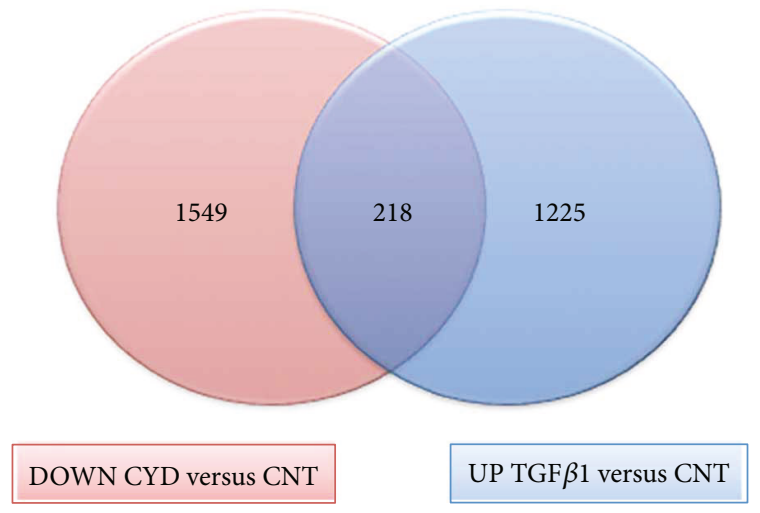

(c)

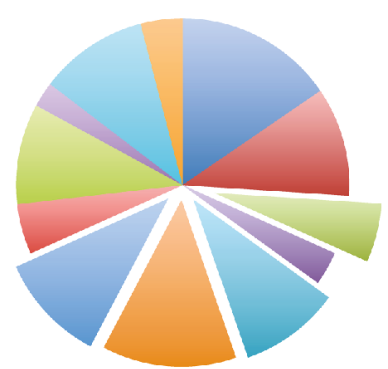

- Hs Insulin signaling WP481 42706

- Hs Integrin-mediated cell adhesion WP185 44862

- Hs Regulation of microtubule cytoskeleton WP2038 47074

- Hs Signaling by insulin receptor WP1913 45215

- Hs TGF beta signaling pathway WP366 45152

- Hs Focal adhesion WP306 41071

- Hs RegulaAon of Actin cytoskeleton WP51 45278

- Hs Wnt signaling pathway WP428 45008

- Hs EGF-EGFR signaling pathway WP437 44600

- Hs Cell junction organization WP1793 44989

- Hs MAPK signaling pathway WP382 41048

- Hs Endochondral ossification WP474 45241

FIGURE 6: Molecular phenotype of CYD-treated hMSCs. (a) Hierarchical clustering of genes that were differentially expressed in CYD-treated and untreated control (CNT) hMSCs. Rows represent individual gene expression for duplicate treated and untreated samples, as indicated. Columns represent individual transcripts. Relative expression levels are presented colorimetrically, according to the scale shown in the color bar. (b) Pie chart showing the pathways with the highest enrichment of genes significantly upregulated in CYD-treated cells. (c) Venn diagram depicting the overlap between the upregulated genes in TGF $\beta 1$-treated cells (UP TGF $\beta 1$ versus CNT) and the downregulated genes in CYD-treated cells (DOWN CYD versus CNT).

actin reorganization, which takes place in the early lineage commitment stage, prior to the upregulation of many adipocytic-specific gene markers [34]. The differentiation of hMSCs into the adipocytic lineage in vitro is known to be influenced by the cytoskeletal tension that results following actin reorganization [32]. Furthermore, TGF $\beta 1 \mathrm{Ca}^{2+}$ signaling is known to regulate osteoblast adhesion through enhanced $\alpha 5$ integrin expression, the formation of focal contacts, and the mediation of cytoskeleton reorganization $[35,36]$. Additionally, the TGF $\beta 1$-mediated stimulation of DNA synthesis in mouse osteoblastic cells is reportedly associated with morphological changes and is accompanied by the enhanced synthesis and polymerization of cytoskeletal proteins [37]. Consistent with this, our data suggests that TGF $\beta 1$ enhances hMSC lineage commitment by regulating the morphology of the actin cytoskeleton, focal adhesion, and endochondral ossification, via the TGF $\beta 1$ and MAPK signaling pathways.

Also consistent with our results are reports that CYDmediated reductions in actin polymerization stimulate adipogenesis, but inhibit osteogenesis [30], suggesting that cytoskeletal modification is a prerequisite for cell fate determination. Our gene expression profiling revealed that the genes FGF1, FGF2, and KRAS, which commonly regulate actin cytoskeleton reorganization, were upregulated and downregulated in TGF $\beta 1$ - and CYD-treated cells, respectively, suggesting that they are involved in the actin polymerization-mediated differentiation of MSCs.

We showed that during osteogenesis, TGF $\beta 1$ treatment reorganized the cytoskeleton, but this reorganization, and thus osteogenesis, could be disturbed by CYD treatment. Conversely, treatment with either TGF $\beta 1$ or CYD promoted adipogenesis. This observation can potentially be explained by considering that TGF $\beta 1$ and CYD promote the formation of different cytoskeleton patterns, both of which support adipogenesis. Alternatively, it is possible that cytoskeletal reorganization leading to adipogenesis can be promoted by both TGF $\beta 1$-dependent and -independent mechanisms, and that CYD-mediated cytoskeletal reorganization cannot override the TGF $\beta 1$-independent mechanism.

We propose a model wherein TGF $\beta 1$ regulates cytoskeletal organization by modulating actin cytoskeleton-related genes, leading to enhanced hMSC differentiation into both osteoblasts and adipocytes (Figure 7). We propose that CYD enhances adipogenesis and inhibits osteogenesis by regulating the expression of a number of key candidate genes, including FGF2, TGF 32 , Plat, EGR2, MEF2D, and IRS1. These genes were modulated by both TGF $\beta 1$ and CYD and 
TABLE 2: Genes involved in osteogenesis-related pathways that are downregulated in CYD-treated hMSCs.

\begin{tabular}{lcccc}
\hline $\begin{array}{l}\text { Endochondral } \\
\text { ossification }\end{array}$ & $\begin{array}{c}\text { Actin } \\
\text { cytoskeleton }\end{array}$ & $\begin{array}{c}\text { Focal } \\
\text { adhesion }\end{array}$ & $\begin{array}{c}\text { TGF } \beta \\
\text { signaling }\end{array}$ & $\begin{array}{c}\text { MAPK } \\
\text { signaling }\end{array}$ \\
\hline FGF2 & FGF1 & ITGA6 & UCHL5 & STMN1 \\
TGFB2 & FGF2 & STYK1 & CDC2 & DUSP1 \\
PLAT & FGF5 & CAV1 & SMURF2 & TRAF2 \\
CALM1 & FGF22 & CAV2 & NEDD9 & BDNF \\
ADAMTS1 & KRAS & CAV3 & STAMBPL1 & MAP3K5 \\
OPG & NRAS & LAMC2 & CCNB2 & ACVR1C \\
& C11orf13 & THBS1 & RBL1 & KRAS \\
& F2R & PXN & MAPK8 & TGFB2 \\
& CRK & RHOB & PARD6A & NRAS \\
& PAK1 & PDPK1 & CAV1 & PPP5C \\
& ARHGEF7 & MYLK2 & TFDP1 & PAK1 \\
& VIL2 & PAK1 & KLF6 & CRK \\
& PXN & MAPK8 & FST & MAPK8 \\
& & BCL2 & SERPINE1 & \\
& & CCND3 & THBS1 & \\
& & CRK & NOG & \\
& & & HRAS & \\
\hline
\end{tabular}

are thus heavily implicated in the determination of hMSC fate. In summary, our study provides novel molecular insights into the role of the intracellular TGF $\beta$ signaling pathway in bone and bone marrow adipose tissue formation. This signaling involves the reorganization of the actin cytoskeleton in order to control the lineage-specific differentiation of hMSCs.

\section{Materials and Methods}

4.1. Cell Culture. An hMSC-TERT cell line was created previously to serve as a model of human primary MSCs by overexpressing human telomerase reverse transcriptase (hTERT) in normal human bone marrow MSCs [38]. This cell line has been extensively characterized and exhibits a similar cellular and molecular phenotype to primary MSCs [39]. For the current experiments, we used a previously characterized subline derived from hMSC-TERT cells, termed hMSC-TERT-CL1 [40]. For ease, this cell line is referred to as "hMSC" for the remainder of the manuscript. Cells were cultured in Dulbecco's modified Eagle's medium (DMEM) supplemented with $4500 \mathrm{mg} / \mathrm{l} \mathrm{D}$-glucose, $4 \mathrm{mM}$ L-glutamine, $110 \mathrm{mg} / \mathrm{l}$ sodium pyruvate, $10 \%$ fetal bovine serum (FBS), $1 \times$ penicillin/streptomycin (pen/strep), and nonessential amino acids. All reagents were purchased from Gibco, USA.

4.2. In Vitro Osteoblastic Differentiation. To induce osteoblastic differentiation, cells were initially grown in standard DMEM growth medium in 6-well plates at a density of $0.3 \times 10^{6}$ cells $/ \mathrm{ml}$. Once $70-80 \%$ confluence was reached, the medium was replaced with DMEM supplemented with osteoblast induction mixture, containing 10\% FBS, 1\% pen/ strep, $50 \mu \mathrm{g} / \mathrm{ml} \mathrm{L-ascorbic} \mathrm{acid} \mathrm{(Wako} \mathrm{Chemicals,} \mathrm{Neuss,}$
TABLE 3: Genes involved in adipogenesis-related pathways that are upregulated in CYD-treated hMSCs.

\begin{tabular}{|c|c|}
\hline Gene symbol & Fold change versus control \\
\hline PPARGC1A & 2.4170778 \\
\hline AGT & 15.447543 \\
\hline GDF10 & 9.77814 \\
\hline BMP2 & 9.539022 \\
\hline UCP1 & 9.416412 \\
\hline SFRP4 & 6.513523 \\
\hline IRS4 & 5.973821 \\
\hline MEF2C & 5.1696005 \\
\hline LPL & 5.150721 \\
\hline PLIN1 & 5.144724 \\
\hline LEP & 5.1005282 \\
\hline $\mathrm{NDN}$ & 5.0982733 \\
\hline CNTFR & 4.9715867 \\
\hline LIF & 3.9070668 \\
\hline PRLR & 3.855135 \\
\hline RXRG & 3.8392398 \\
\hline EGR2 & 3.6894956 \\
\hline PCK1 & 3.6815107 \\
\hline CYP26A1 & 3.170688 \\
\hline TGFBI & 3.1407108 \\
\hline STAT2 & 3.0656292 \\
\hline BMP3 & 2.9982927 \\
\hline IGF1 & 2.9808753 \\
\hline PTGIS & 2.8547947 \\
\hline INSR & 2.8151898 \\
\hline SLC2A4 & 2.747039 \\
\hline CEBPB & 2.7001002 \\
\hline IRS1 & 2.5992496 \\
\hline LPIN1 & 2.579549 \\
\hline AHRR & 2.5087466 \\
\hline IL6 & 2.4654725 \\
\hline IRS2 & 2.3497624 \\
\hline STAT5A & 2.2441745 \\
\hline CEBPA & 2.2439373 \\
\hline SCD & 2.216643 \\
\hline STAT1 & 2.205384 \\
\hline SPOCK1 & 2.201062 \\
\hline SREBF1 & 2.0996578 \\
\hline EPAS1 & 2.0842645 \\
\hline MEF2D & 2.0606902 \\
\hline BMP1 & 2.0168457 \\
\hline LPIN3 & 2.0103807 \\
\hline
\end{tabular}

Germany), $10 \mathrm{mM} \beta$-glycerophosphate (Sigma), $10 \mathrm{nM}$ calcitriol (1 $\alpha, 25$-dihydroxyvitamin $\mathrm{D}_{3}$; Sigma), and $10 \mathrm{nM}$ dexamethasone (Sigma). The medium was replaced 3 times per week. Cells were cultured in standard culture medium in parallel as controls. 
TABLE 4: Genes involved in both osteogenesis- and adipogenesis-related pathways that are significantly changed in TGF $\beta$-treated cells and CYD-treated cells.

\begin{tabular}{|c|c|c|c|c|c|}
\hline Endochondral ossification & Actin cytoskeleton & Focal adhesion & TGFB signaling & MAPK signaling & Adipogenesis \\
\hline TGFB2 & FGF1 & CAV2 & NEDD9 & TGFB2 & EGR2 \\
\hline FGF2 & FGF2 & MAPK8 & MAPK8 & MAPK8 & IRS1 \\
\hline \multirow[t]{2}{*}{ PLAT } & KRAS & LAMC2 & & KRAS & MEF2D \\
\hline & & & & DUSP1 & \\
\hline
\end{tabular}

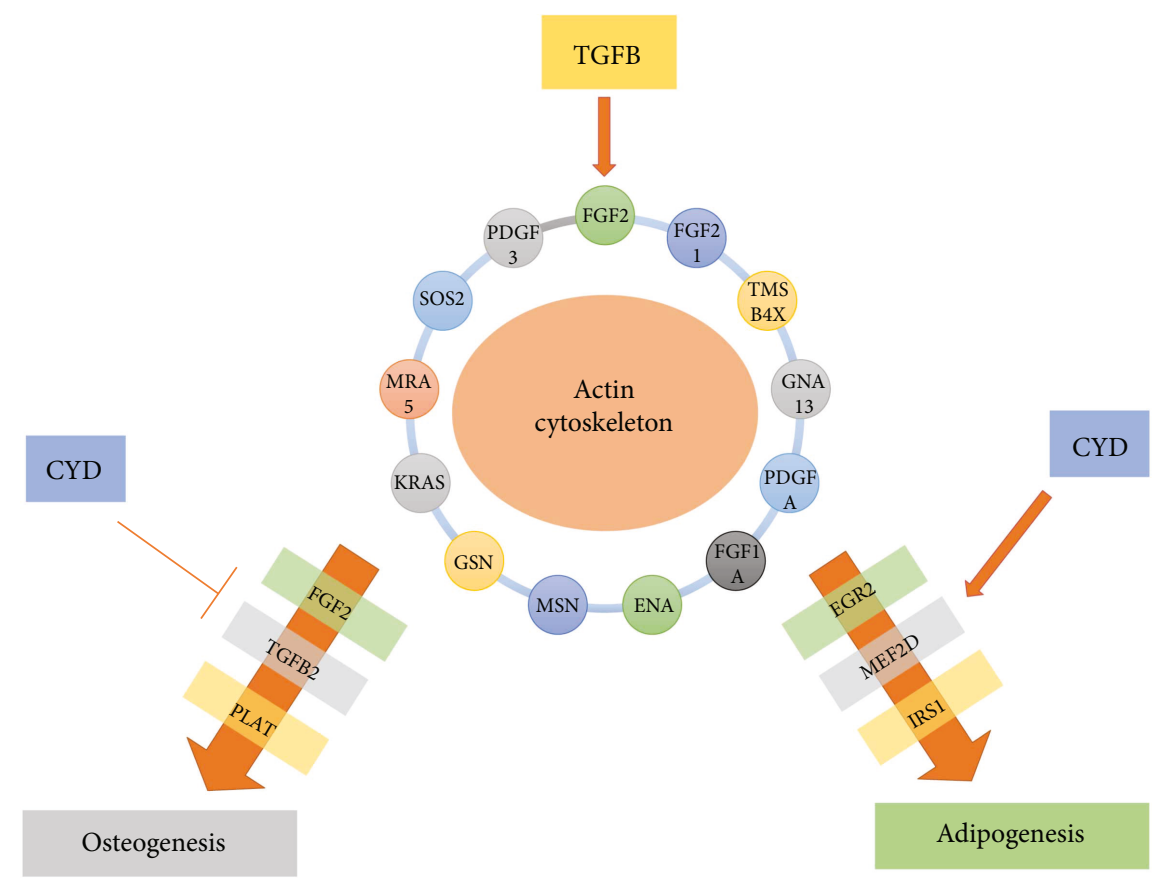

FIGURE 7: TGF $\beta 1$ signaling in hMSC differentiation. Schematic showing how TGF $\beta$ and CYD affect hMSC osteogenic and adipogenic differentiation through the modulation of genes associated with the actin cytoskeletal pathway. Suggested downstream targets are also shown.

4.3. In Vitro Adipocytic Differentiation. To induce adipocytic differentiation, cells were initially grown in standard DMEM growth medium in 6-well plates at a density of $0.3 \times 10^{6}$ cells/ ml. Once $90-100 \%$ confluence was reached, the medium was replaced with DMEM supplemented with adipogenic induction mixture, containing 10\% FBS, $10 \%$ horse serum (Sigma), $1 \%$ pen/strep, $100 \mathrm{nM}$ dexamethasone, $0.45 \mathrm{mM}$ isobutyl methylxanthine [41] (Sigma), $3 \mu \mathrm{g} / \mathrm{ml}$ insulin (Sigma), and $1 \mu \mathrm{M}$ rosiglitazone [42] (Novo Nordisk, Bagsvaerd, Denmark). The medium was replaced 3 times per week, and cells cultured in parallel in standard culture medium were used as controls.

\subsection{Cytochemical Staining}

4.4.1. Alizarin Red S Staining for Mineralized Matrix. Once cells had grown sufficiently, the cell monolayer was washed with phosphate-buffered saline (PBS) and then fixed with $4 \%$ paraformaldehyde for 15 minutes at room temperature. Cells were then rinsed 3 times in distilled water and stained with 2\% alizarin red S Stain (Cat. number 0223; ScienCell, Carlsbad, CA, USA) for 20-30 minutes at room temperature. Cells were washed further 3-5 times with water to remove excess dye and then stored in water to prevent them drying out. Cells were then visualized using an inverted microscope (ZEISS AX10). To quantify alizarin red S staining, and hence mineralization, plates were air dried, and then the alizarin red $S$ dye was eluted by adding $800 \mu \mathrm{l}$ acetic acid to each well and incubating for 30 minutes at room temperature, as described previously [43]. The stain was then quantified by measuring the absorbance at $405 \mathrm{~nm}$ with an Epoch spectrophotometer (BioTek Inc., Winooski, VT, USA).

4.4.2. OsteoImage Mineralization Assay. The formation of mineralized matrix in vitro was quantified using an OsteoImage mineralization assay kit according to manufacturer's instructions (Cat. number PA-1503; Lonza, USA). Briefly, culture medium was removed, and cells were washed once with PBS and then fixed with 70\% cold ethanol for 20 minutes. Next, diluted staining reagent was added at a level recommended by the manufacturer, and plates were incubated in the dark for 30 minutes at room temperature. The cells were then washed, and staining was quantified using a fluorescence plate reader (Molecular Devices Co., Sunnyvale, CA, USA) with excitation and emission wavelengths of 492 and $520 \mathrm{~nm}$, respectively. 
4.4.3. Oil Red O Staining for Lipid Droplets. Cytoplasmic lipid droplets within mature adipocytes were visualized using Oil red $\mathrm{O}$ staining. Cells were washed with PBS, fixed in $4 \%$ formaldehyde for 10 minutes at room temperature, rinsed once with 3\% isopropanol, and then stained for 1 hour at room temperature with filtered Oil red $\mathrm{O}$ staining solution (prepared by dissolving $0.5 \mathrm{~g}$ Oil red $\mathrm{O}$ powder in 60\% isopropanol). In order to quantify mature adipocytes, Oil red O stain was eluted from cells by adding 100\% isopropanol to each well, and then the absorbance at $510 \mathrm{~nm}$ was measured using an Epoch spectrophotometer.

4.4.4. Nile Red Staining for the Quantification of Mature Adipocytes. A $1 \mathrm{mg} / \mathrm{ml}$ stock solution of Nile red fluorescent stain was prepared in DMSO and stored in the dark at $-20^{\circ} \mathrm{C}$. Cultured undifferentiated and differentiated cells were fixed in $4 \%$ paraformaldehyde (Sigma) for 15 minutes and then washed once with PBS. PBS was then removed, and cells were stained with $5 \mu \mathrm{g} / \mathrm{ml}$ Nile red stain in PBS for 10 minutes at room temperature. The fluorescence signal was measured using a SpectraMax/M5 fluorescence spectrophotometer (Molecular Devices Co.) in bottomwell scan mode. Nine readings were taken per well using excitation and emission wavelengths of $485 \mathrm{~nm}$ and $572 \mathrm{~nm}$, respectively.

4.5. Quantitative Real-Time PCR ( $q R T-P C R)$. Total RNA was extracted from cells using a PureLink RNA mini kit (Cat number 12183018A; Ambion, USA) according to manufacturer's recommendations and quantified using a NanoDrop 2000 spectrophotometer (Thermo Scientific, USA). Complementary DNA (cDNA) was synthesized from $1 \mu \mathrm{g}$ RNA using a high-capacity cDNA reverse transcription kit (Applied Biosystems, USA) and a MultiGene thermal cycler (Labnet) according to manufacturer's instructions. Relative mRNA levels were inferred from the cDNAs using Power SYBR Green master mix (Applied Biosystems, UK) and TaqMan Universal master mix II, no UNG (Applied Biosystems, USA), both according to manufacturer's instructions, and a real-time PCR detection system (Applied Biosystems). Relative mRNA levels were normalized to the reference gene GAPDH, and then gene expression quantification was performed using a comparative $\mathrm{Ct}$ method, wherein $\Delta \mathrm{CT}$ is defined as the difference between the target and reference gene CT values. Primers are listed in Supplementary Tables S7 and S8. These primers were either TaqMan primers (Applied Biosystems) or custom primers whose sequences have been published previously.

4.6. Global Gene Expression Profiling by Microarray. Total RNA was extracted from cells using a PureLink RNA mini kit, according to manufacturer's recommendations. One hundred and fifty nanograms of total RNA was then labeled and hybridized to a SurePrint G3 Human GE $8 \times 60 \mathrm{~K}$ microarray chip (Agilent Technologies). All microarray experiments were conducted by the Microarray Core Facility (Stem Cell Unit, College of Medicine, King Saud University). Normalization and data analyses were performed using GeneSpring GX software (Agilent Technologies), and pathway analysis was conducted using the Single Experiment Pathway analysis feature of the GeneSpring 12.0 software package (Agilent Technologies) as described previously (66). In addition, we used the web-based software DAVID Bioinformatics Resources 6.8, where all genes that were upregulated by TGfb were uploaded into DAVID and signaling pathways were achieved. Significant changes were defined as a fold change of $\geq 2$ and $p<0.02$.

\subsection{Cell Proliferation Assays}

4.7.1. AlamarBlue Cell Viability Assay. Cell viability was measured using alamarBlue assay reagent (AbD Serotec, Raleigh, NC, USA) according to manufacturer's recommendations. Briefly, cells were cultured in 96-well plates in $100 \mu \mathrm{l}$ of the appropriate medium before $10 \mu \mathrm{l}$ alamarBlue substrate was added at the indicated time points. Plates were then incubated in the dark at $37^{\circ} \mathrm{C}$ for 1 hour. AlamarBlue fluorescence was then detected using a Synergy II microplate reader (BioTek Inc.) with excitation and emission wavelengths of $530 \mathrm{~nm}$ and $590 \mathrm{~nm}$, respectively.

4.8. RTCA Cell Proliferation Assay. An xCELLigence RTCA (real-time cell analysis) DP system (ACEA Biosciences Inc., San Diego, CA) was used to measure the rate of cellular proliferation according to manufacturer's protocol. Briefly, $100 \mu \mathrm{l}$ DMEM supplemented with 10\% FBS was loaded onto each well of an E-plate 16 chamber slide, which was then placed inside the humidified incubator of the RTCA DP analyzer for 1 hour at $37^{\circ} \mathrm{C}$ to allow the membrane surface and medium to equilibrate. After 1 hour, background measurements were performed. Next, 5000 cells $/ 100 \mu \mathrm{l}$ DMEM $+10 \%$ FBS were added per well, and measurements were recorded at 15-minute intervals for various total durations, depending on the experimental setup.

4.9. Transmission Electron Microscopy (TEM). For TEM, cells were trypsinized, washed with PBS, pelleted, and then fixed in 2.5\% glutaraldehyde (Cat. number 16500; Electron Microscopy Sciences) in $0.1 \mathrm{M}$ phosphate buffer ( $\mathrm{pH} 7.2)$ at $4^{\circ} \mathrm{C}$ for 4 hours. Next, the cells were washed in $0.1 \mathrm{M}$ phosphate buffer ( $\mathrm{pH}$ 7.2) 3 times for 30 minutes each and then treated with $1 \%$ osmium tetroxide $\left(\mathrm{OsO}_{4}\right)$ in $0.1 \mathrm{M}$ phosphate buffer ( $\mathrm{pH}$ 7.2) for 2 hours. Cells were then dehydrated in increasing concentrations of ethanol $(10 \%, 30 \%, 50 \%$, $70 \%, 90 \%$, and $100 \%$ ) for 15 minutes each, before being resuspended in acetone and incubated for 15 minutes. The resulting cell suspension was then aliquoted into BEEM ${ }^{\circledR}$ embedding capsules and infiltrated firstly with a $2: 1$ acetone:resin mixture for 1 hour and secondly with a $1: 2$ acetone:resin mixture for 1 hour. Following infiltration, the BEEM capsules were centrifuged at $2500 \mathrm{rpm}$ for 5 minutes and embedded in pure resin for 2 hours. The resin was then polymerized by baking in an oven at $70^{\circ} \mathrm{C}$ for 12 hours. Semithin sections $(0.5 \mu \mathrm{m}$ thickness) were prepared and stained with $1 \%$ toluidine blue. Ultrathin sections $(70 \mathrm{~nm}$ thickness) were prepared and mounted on copper grids and then stained firstly with uranyl acetate (saturated ethanol solution) for 30 minutes, rinsed with double distilled water and then stained with Reynold's lead citrate solution for 5 
minutes before a final rinse with distilled water. The contrasted ultrathin sections were examined and photographed under a JEOL 1010 transmission electron microscope (JEOL, Tokyo, Japan).

4.10. Statistical Analysis. All results are presented as the mean \pm SD of at least 3 independent experiments. Differences between groups were assessed using Student's $t$-test, and $p$ values $<0.05$ were considered statistically significant.

\section{Conflicts of Interest}

The authors declare that they have no conflicts of interest.

\section{Acknowledgments}

The authors would like to extend their sincere appreciation to the Deanship of Scientific Research at King Saud University for its funding of this research through the Research Group Project no. RGP-1438-032.

\section{Supplementary Materials}

Supplementary 1. Figure S1: DAVID microarray functional gene analysis. One thousand nine hundred genes were uploaded to DAVID online software. KEGG pathway analysis showed many interested pathways which are upregulated after TGFb-1 treatment of hBMCs. Here, we show the top most upregulated pathways which include key osteoblast differentiation pathways.

Supplementary 2. Table S1: whole genome microarray mRNA data showing gene ENTITIES for TG1 versus CNT DOWN 1298 genes.

Supplementary 3. Table S2: whole genome microarray mRNA data showing gene ENTITIES for TG1 versus CNT UP 1932 genes.

Supplementary 4. Table S3: upregulated biological processes and related genes in TGFB1-treated cells using GO analysis.

Supplementary 5. Table S4: ultrastructural characteristics of CL1 cells under different treatment conditions.

Supplementary 6. Table S5: whole genome microarray mRNA data showing gene entities for CYD versus CNT up to 10,855 genes.

Supplementary 7. Table S6: whole genome microarray mRNA data showing gene entities for CYD versus CNT DOWN 2523 genes.

Supplementary 8. Table S7: real-time PCR human primer sequences used in this study.

Supplementary 9. Table S8: TAQMAN real-time PCR primers.

\section{References}

[1] N. Oshimori and E. Fuchs, "The harmonies played by TGF- $\beta$ in stem cell biology," Cell Stem Cell, vol. 11, no. 6, pp. 751$764,2012$.
[2] J. Massagué, J. Seoane, and D. Wotton, "Smad transcription factors," Genes \& Development, vol. 19, no. 23, pp. 27832810, 2005.

[3] J. Pfeilschifter, L. Bonewald, and G. R. Mundy, "Characterization of the latent transforming growth factor $B$ complex in bone," Journal of Bone and Mineral Research, vol. 5, no. 1, pp. 49-58, 1990.

[4] D. Sheppard, "Transforming growth factor $\beta$ : a central modulator of pulmonary and airway inflammation and fibrosis," Proceedings of the American Thoracic Society, vol. 3, no. 5, pp. 413-417, 2006.

[5] Y. Tang, X. Wu, W. Lei et al., “TGF- $\beta 1$-induced migration of bone mesenchymal stem cells couples bone resorption with formation," Nature Medicine, vol. 15, no. 7, pp. 757-765, 2009.

[6] K. Janssens, P. ten Dijke, S. Janssens, and W. Van Hul, "Transforming growth factor- $\beta 1$ to the bone," Endocrine Reviews, vol. 26, no. 6, pp. 743-774, 2005.

[7] L. Chen, K. Shi, C. E. Frary et al., "Inhibiting actin depolymerization enhances osteoblast differentiation and bone formation in human stromal stem cells," Stem Cell Research, vol. 15, no. 2, pp. 281-289, 2015.

[8] S. Ono, "Mechanism of depolymerization and severing of actin filaments and its significance in cytoskeletal dynamics," International Review of Cytology, vol. 258, pp. 1-82, 2007.

[9] P. Lappalainen and D. G. Drubin, "Cofilin promotes rapid actin filament turnover in vivo," Nature, vol. 388, no. 6637, pp. 78-82, 1997.

[10] D. A. Fletcher and R. D. Mullins, "Cell mechanics and the cytoskeleton,” Nature, vol. 463, no. 7280, pp. 485-492, 2010.

[11] G. Yourek, M. A. Hussain, and J. J. Mao, "Cytoskeletal changes of mesenchymal stem cells during differentiation," ASAIO Journal, vol. 53, no. 2, pp. 219-228, 2007.

[12] M. Elsafadi, M. Manikandan, R. A. Dawud et al., "Transgelin is a TGF $\beta$-inducible gene that regulates osteoblastic and adipogenic differentiation of human skeletal stem cells through actin cytoskeleton organization," Cell Death \& Disease, vol. 7, no. 8, article e2321, 2016.

[13] H. Jian, X. Shen, I. Liu, M. Semenov, X. He, and X. F. Wang, "Smad3-dependent nuclear translocation of $\beta$-catenin is required for TGF- $\beta 1$-induced proliferation of bone marrowderived adult human mesenchymal stem cells," Genes \& Development, vol. 20, no. 6, pp. 666-674, 2006.

[14] A. Erlebacher, E. H. Filvaroff, J. Q. Ye, and R. Derynck, "Osteoblastic responses to TGF- $\beta$ during bone remodeling," Molecular Biology of the Cell, vol. 9, no. 7, pp. 1903-1918, 1998.

[15] E. Filvaroff, A. Erlebacher, J. Ye et al., "Inhibition of TGF-beta receptor signaling in osteoblasts leads to decreased bone remodeling and increased trabecular bone mass," Development, vol. 126, no. 19, pp. 4267-4279, 1999.

[16] J. M. Hock, E. Canalis, and M. Centrella, "Transforming growth factor- $\beta$ stimulates bone matrix apposition and bone cell replication in cultured fetal rat calvariae," Endocrinology, vol. 126, no. 1, pp. 421-426, 1990.

[17] S. Spinella-Jaegle, S. Roman-Roman, C. Faucheu et al., "Opposite effects of bone morphogenetic protein-2 and transforming growth factor- $\beta 1$ on osteoblast differentiation," Bone, vol. 29, no. 4 , pp. 323-330, 2001.

[18] R. A. Ignotz and J. Massagué, “Type beta transforming growth factor controls the adipogenic differentiation of 3T3 fibroblasts," Proceedings of the National Academy of Sciences of 
the United States of America, vol. 82, no. 24, pp. 8530-8534, 1985.

[19] T. Teruel, A. M. Valverde, M. Benito, and M. Lorenzo, "Transforming growth factor $\beta_{1}$ induces differentiation-specific gene expression in fetal rat brown adipocytes," FEBS Letters, vol. 364, no. 2, pp. 193-197, 1995.

[20] S. Maeda, M. Hayashi, S. Komiya, T. Imamura, and K. Miyazono, "Endogenous TGF- $\beta$ signaling suppresses maturation of osteoblastic mesenchymal cells," The EMBO Journal, vol. 23, no. 3, pp. 552-563, 2004.

[21] H. Yu, M. Königshoff, A. Jayachandran et al., "Transgelin is a direct target of TGF- $\beta$ /Smad3-dependent epithelial cell migration in lung fibrosis," The FASEB Journal, vol. 22, no. 6, pp. 1778-1789, 2008.

[22] M. Centrella, T. L. McCarthy, and E. Canalis, “Transforming growth factor beta is a bifunctional regulator of replication and collagen synthesis in osteoblast-enriched cell cultures from fetal rat bone," The Journal of Biological Chemistry, vol. 262, no. 6, pp. 2869-2874, 1987.

[23] P. G. Robey, M. F. Young, K. C. Flanders et al., "Osteoblasts synthesize and respond to transforming growth factor-type beta (TGF-beta) in vitro," The Journal of Cell Biology, vol. 105, no. 1, pp. 457-463, 1987.

[24] T. L. Chen and R. L. Bates, "Recombinant human transforming growth factor $\beta_{1}$ modulates bone remodeling in a mineralizing bone organ culture," Journal of Bone and Mineral Research, vol. 8, no. 4, pp. 423-434, 1993.

[25] T. Yamada, N. Kamiya, D. Harada, and M. Takagi, "Effects of transforming growth factor- $\beta 1$ on the gene expression of decorin, biglycan, and alkaline phosphatase in osteoblast precursor cells and more differentiated osteoblast cells," The Histochemical Journal, vol. 31, no. 10, pp. 687-694, 1999.

[26] M. Kassem, M. Kveiborg, and E. F. Eriksen, "Production and action of transforming growth factor- $\beta$ in human osteoblast cultures: dependence on cell differentiation and modulation by calcitriol," European Journal of Clinical Investigation, vol. 30, no. 5, pp. 429-437, 2000.

[27] M. Noda and G. A. Rodan, “Type $\beta$ transforming growth factor (TGF $\beta$ ) regulation of alkaline phosphatase expression and other phenotype-related mRNAs in osteoblastic rat osteosarcoma cells," Journal of Cellular Physiology, vol. 133, no. 3, pp. 426-437, 1987.

[28] M. E. Antosz, C. G. Bellows, and J. E. Aubin, "Effects of transforming growth factor $\beta$ and epidermal growth factor on cell proliferation and the formation of bone nodules in isolated fetal rat calvaria cells," Journal of Cellular Physiology, vol. 140, no. 2, pp. 386-395, 1989.

[29] B. M. Gumbiner, "Cell adhesion: the molecular basis of tissue architecture and morphogenesis," Cell, vol. 84, no. 3, pp. 345-357, 1996.

[30] H. Sonowal, A. Kumar, J. Bhattacharyya, P. K. Gogoi, and B. G. Jaganathan, "Inhibition of actin polymerization decreases osteogeneic differentiation of mesenchymal stem cells through p38 MAPK pathway," Journal of Biomedical Science, vol. 20, no. 1, p. 71, 2013.

[31] N. P. Talele, J. Fradette, J. E. Davies, A. Kapus, and B. Hinz, "Expression of $\alpha$-smooth muscle actin determines the fate of mesenchymal stromal cells," Stem Cell Reports, vol. 4, no. 6, pp. 1016-1030, 2015.

[32] R. McBeath, D. M. Pirone, C. M. Nelson, K. Bhadriraju, and C. S. Chen, "Cell shape, cytoskeletal tension, and RhoA regulate stem cell lineage commitment," Developmental Cell, vol. 6, no. 4, pp. 483-495, 2004.

[33] J. Y. Fan, J. L. Carpentier, E. van Obberghen, C. Grunfeld, P. Gorden, and L. Orci, "Morphological changes of the 3T3L1 fibroblast plasma membrane upon differentiation to the adipocyte form," Journal of Cell Science, vol. 61, pp. 219-230, 1983.

[34] J. Antras, F. Hilliou, G. Redziniak, and J. Pairault, "Decreased biosynthesis of actin and cellular fibronectin during adipose conversion of 3T3-F442A cells. Reorganization of the cytoarchitecture and extracellular matrix fibronectin," Biology of the Cell, vol. 66, no. 3, pp. 247-254, 1989.

[35] L. J. Nesti, E. J. Caterson, M. Wang et al., “TGF- $\beta 1$-stimulated osteoblasts require intracellular calcium signaling for enhanced $\alpha 5$ integrin expression," Annals of the New York Academy of Sciences, vol. 961, no. 1, pp. 178-182, 2002.

[36] L. J. Nesti, E. J. Caterson, M. Wang et al., "TGF- $\beta 1$ calcium signaling increases $\alpha 5$ integrin expression in osteoblasts," Journal of Orthopaedic Research, vol. 20, no. 5, pp. 1042-1049, 2002.

[37] A. Lomri and P. J. Marie, "Effects of transforming growth factor type $\beta$ on expression of cytoskeletal proteins in endosteal mouse osteoblastic cells," Bone, vol. 11, no. 6, pp. 445-451, 1990.

[38] J. L. Simonsen, C. Rosada, N. Serakinci et al., "Telomerase expression extends the proliferative life-span and maintains the osteogenic potential of human bone marrow stromal cells," Nature Biotechnology, vol. 20, no. 6, pp. 592-596, 2002.

[39] M. Al-Nbaheen, R. Vishnubalaji, D. Ali et al., "Human stromal (mesenchymal) stem cells from bone marrow, adipose tissue and skin exhibit differences in molecular phenotype and differentiation potential," Stem Cell Reviews, vol. 9, no. 1, pp. 32-43, 2013.

[40] M. Elsafadi, M. Manikandan, M. Atteya et al., "Characterization of cellular and molecular heterogeneity of bone marrow stromal cells," Stem Cells International, vol. 2016, Article ID 9378081, 18 pages, 2016.

[41] A. Hildebrand, M. Romarís, L. M. Rasmussen et al., "Interaction of the small interstitial proteoglycans biglycan, decorin and fibromodulin with transforming growth factor $\beta$," The Biochemical Journal, vol. 302, no. 2, pp. 527-534, 1994.

[42] R. Serra and C. Chang, "TGF- $\beta$ signaling in human skeletal and patterning disorders," Birth Defects Research Part C: Embryo Today: Reviews, vol. 69, no. 4, pp. 333-351, 2003.

[43] C. A. Gregory, W. G. Gunn, A. Peister, and D. J. Prockop, “An alizarin red-based assay of mineralization by adherent cells in culture: comparison with cetylpyridinium chloride extraction," Analytical Biochemistry, vol. 329, no. 1, pp. 77-84, 2004. 


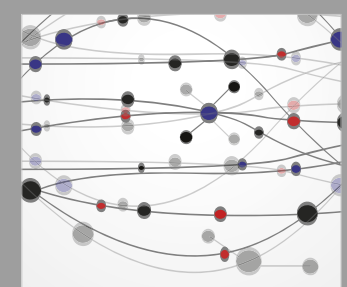

The Scientific World Journal
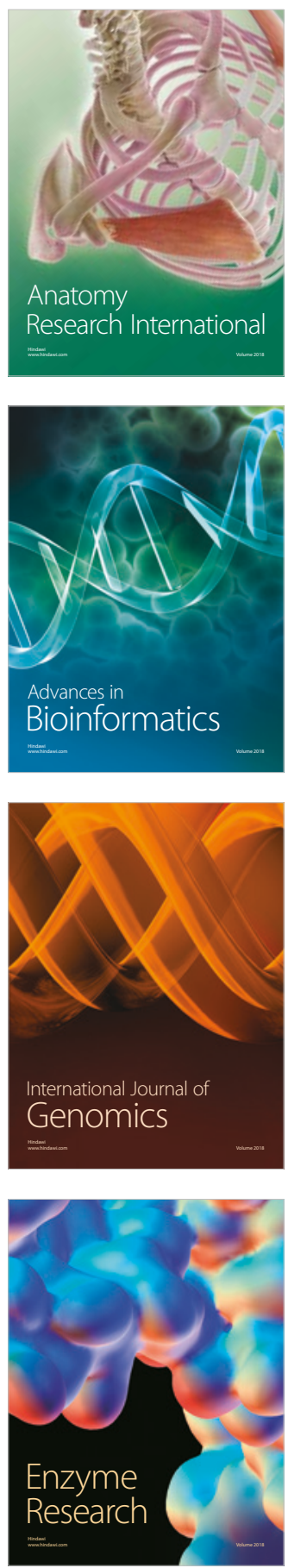
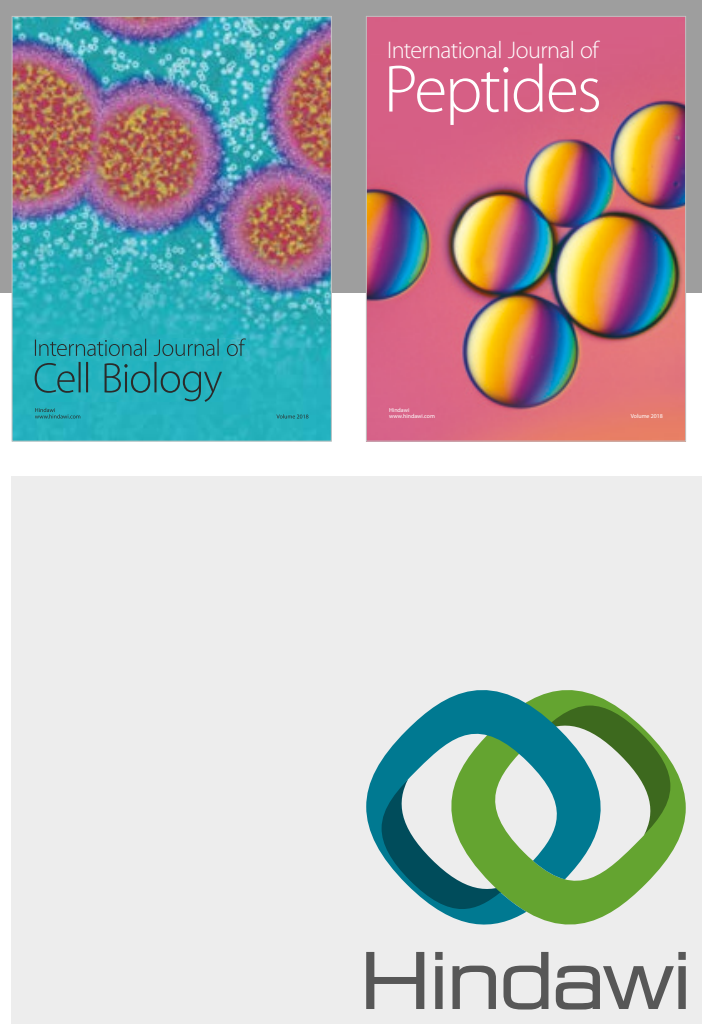

Submit your manuscripts at

www.hindawi.com
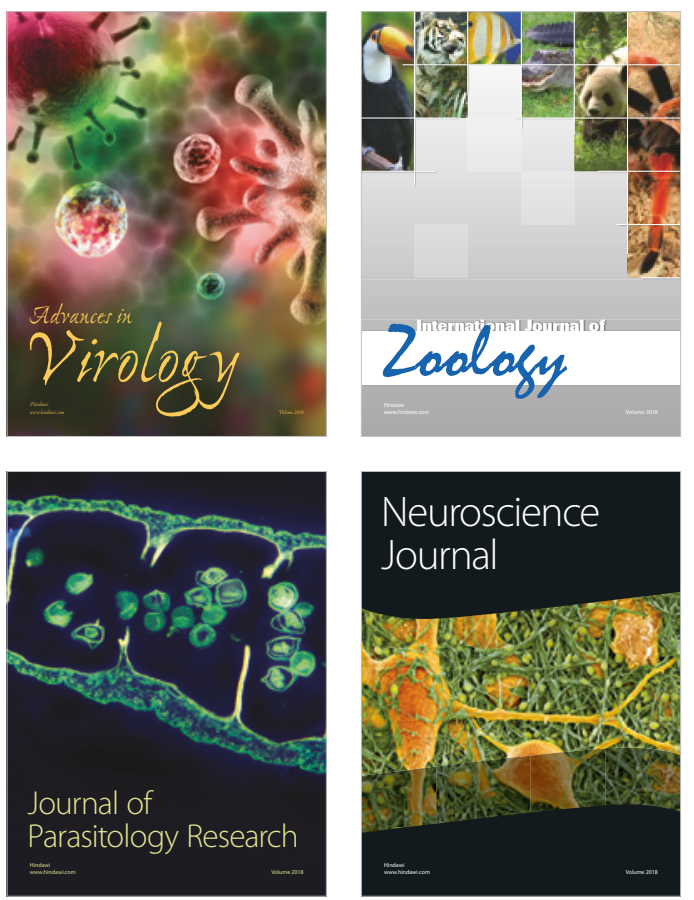
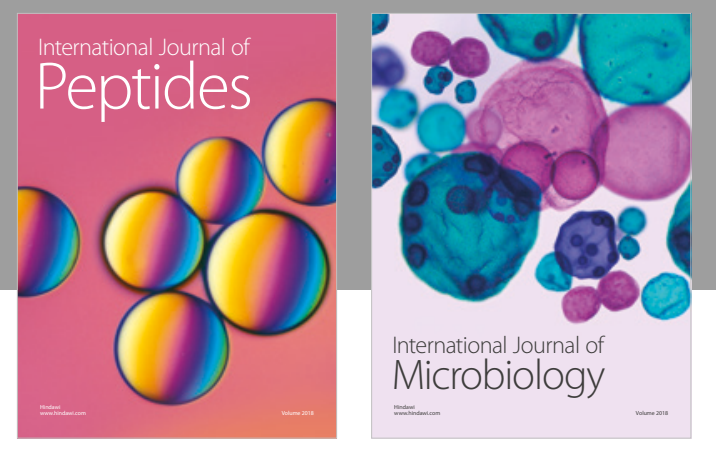

nternational Journal of Microbiology
Journal of
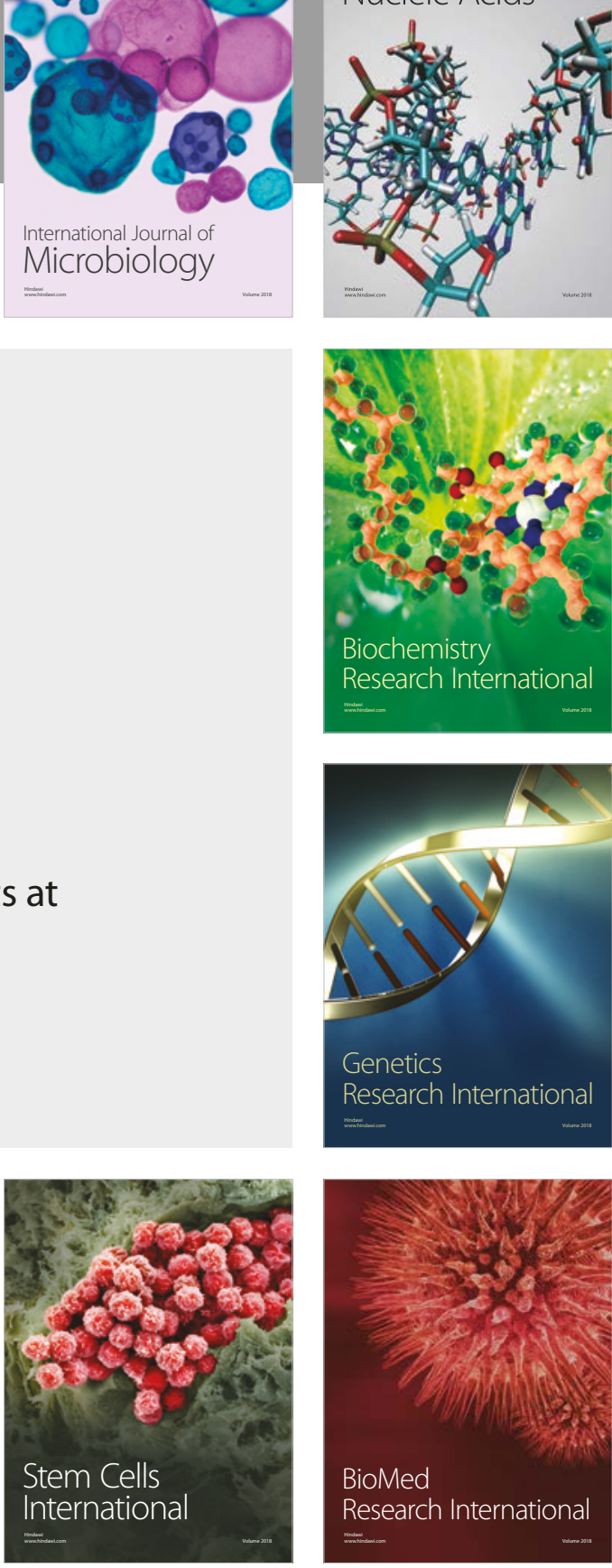
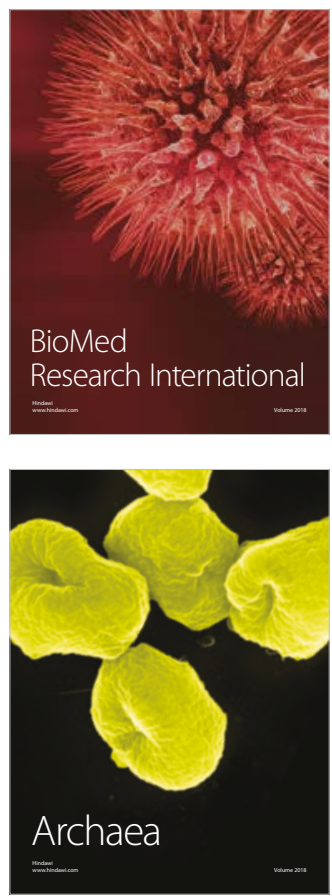